\title{
Calcium Permeability of the Neuronal Nuclear Envelope: Evaluation Using Confocal Volumes and Intracellular Perfusion
}

\author{
Donald M. O'Malley \\ Howard Hughes Medical Institute and Department of Neurobiology and Behavior, SUNY at Stony Brook, New York 11794- \\ 5230
}

In many calcium-imaging studies, the nuclear envelope appears to maintain a gradient of free calcium between the nucleus and cytosol. This issue was examined by loading amphibian sympathetic neurons with the calcium indicator fluo 3 via whole-cell patch clamping. Confocal optical sectioning allowed acquisition of independent calibration curves for the nucleus and cytoplasm. Cells were loaded with free calcium levels ranging from $10 \mathrm{~nm}$ to $50 \mu \mathrm{M}$, using $10 \mathrm{~mm}$ BAPTA to control free calcium. The nuclear fluorescence was usually about $130 \%$ brighter than the cytoplasmic fluorescence. Had the increased nuclear fluorescence been due to a calcium gradient, then, as fluo 3 was saturated with calcium in both compartments, the fluorescence gradient should have gradually disappeared. Instead, with free-calcium in the pipette set at $50 \mu \mathrm{M}$, about five times the level required to nearly saturate fluo 3 , the nuclear/cytoplasmic (N/C) fluorescence ratio was not decreased but instead increased slightly.

Perfusion of the patch pipette was used in conjunction with imaging to confirm that cytoplasmic fluo 3 was saturated with calcium. After loading cells with $10 \mathrm{~nm}$ free calcium, the patch pipette was perfused with high calcium $(10 \mu \mathrm{m})$. Again, the $N / C$ fluorescence ratio increased at high calcium. The effectiveness of patch-pipette perfusion in changing cellular free calcium levels was indicated by the degree of fluorescence increase-both nuclear and cytosolic compartments showed a roughly $\mathbf{2 0 - f o l d ~ i n c r e a s e ~ i n ~ f l u o r e s c e n c e , ~ t h a t ~ i s , ~}$ most of the dynamic range observed in test droplets. To confirm further that cytoplasmic fluo 3 was saturated, cells were perfused with manganese, which binds with very high affinity to fluo 3. Manganese rapidly entered the cytoplasm and nucleus, causing a large increase in fluorescence, but the $\mathrm{N} / \mathrm{C}$ fluorescence ratio remained relatively constant. Because free manganese in the pipette was 50,000 times the amount required to saturate fluo 3 , the greater nuclear fluorescence probably results from additional fluo 3 in the nucleus rather than from calcium or manganese gradients.

To gauge further the permeability of the nuclear envelope, the diffusion of calcium was visualized. Under voltage clamp,

Received June 17, 1993; revised Feb. 15, 1994; accepted Apr. 13, 1994.

I thank Dr. Paul Adams for enthusiastically supporting and guiding this work. I am indebted to Barry Burbach for instruction and technical assistance, to Dr. Shan Ping Yu for instruction in intracellular perfusion, and to Dr. Neil V. Marrion for advice and critical reading of the manuscript. This work was supported by NIH Fellowship F32 NS09113-01 and the Howard Hughes Medical Institute.

Correspondence should be addressed to Donald M. O'Malley, Department of Neurobiology and Behavior, SUNY, Stony Brook, NY 11794-5230.

Copyright (C) 1994 Society for Neuroscience $0270-6474 / 94 / 145741-18 \$ 05.00 / 0$ calcium channels were opened for periods ranging from 5 to 200 msec. Peak calcium levels were observed within 2 $\mu \mathrm{m}$ of the plasma membrane, and declined as calcium diffused into the cell. The nuclear fluorescence increased more than cytosolic fluorescence, but this apparent "amplification" was eliminated by correcting for autofluorescence. Use of cells cultured on glass coverslips and a high-NA microscope objective allowed a satisfactory correction. The size of nuclear responses was proportional to the size of the calcium influx, with a $5 \mathrm{msec}$ depolarization raising nuclear calcium by roughly $50 \mathrm{~nm}$. In other experiments, nuclear calcium rose by about $10 \mathrm{~nm}$ in response to single action potentials. Line scans acquired at 2 msec intervals showed influx of calcium into the nucleus within 10-20 msec after the calcium transient arrived at the nuclear envelope. In each instance, out of 103 trials in $\mathbf{4 9}$ cells, cytosolic calcium transients spread directly into the nucleus.

The simplest explanation is that calcium freely diffuses through the nuclear pores. This is consistent with numerous reports showing that molecules smaller than $20 \mathrm{kDa}$ pass through nuclear pores in an unrestricted fashion. Diverse neural phenomena such as learning, ischemic damage, and Alzheimer's disease might directly involve actions of nuclear calcium. If so, the permeability of the nuclear envelope will influence their course.

[Key words: calcium imaging, nucleus, confocal, perfusion, sympathetic, Fluo-3]

Can a gradient of free calcium be sustained across the doublemembrane structure of the nuclear envelope? The use of fluorescent calcium indicators to produce "calcium images" of nerve cells has renewed interest in this controversial issue. Using the ratiometric calcium indicator fura 2, Marrion and coworkers have loaded cultured sympathetic neurons via whole-cell patch clamp, and have observed esscntially cqual levels of frec calcium in the nucleus and cytosol at rest and after stimulation (Marrion et al., 1991; Marrion and Adams, 1992). Similar results were obtained with neurons in intact sympathetic ganglia (Nohmi et al., 1992) and with chromaffin cells (Neher and Augustine, 1992). In contrast, Hernandez-Cruz et al. (1990, 1991), using a nonratiometric dye, fluo 3 , as well as fura 2 , have claimed that nuclear calcium increases more than cytosolic calcium after depolarization of sympathetic and sensory neurons. This would require an amplification mechanism, presumably residing in the nuclear envelope. Przywara's group, using indo 1, reported that nuclear calcium levels rise faster and higher than cytosolic calcium levels (Przywara et al., 1991). More recently, Segal and Manor (1992) and Birch et al. (1992), using hippocampal neu- 
rons loaded with fluo 3-AM, have reported amplified nuclear calcium signals and, in the latter study, even higher levels of free calcium in the nucleolus.

There are numerous reports of standing nuclear/cytosolic $(\mathrm{N} / \mathrm{C})$ calcium gradicnts in non-ncuronal cells. Early ratio-imaging experiments, using fura-2, report sustained $\mathrm{N} / \mathrm{C}$ calcium gradients in smooth muscle (Williams et al., 1985, 1987; Neylon et al., 1990). In these studies, the nucleus rests at a different level of free calcium than the cytosol and appears to be shielded from cytoplasmic calcium transients. This would imply that the nuclear envelope is a barrier to the diffusion of calcium. Other studies of smooth muscle, using either fura 2 or indo 1, have observed amplified nuclear calcium signals (Herman et al., 1987; Himpens et al., 1992a,b). What both groups of studies have in common is the observation of substantial N/C calcium gradients that can persist for the duration of the experiments.

There are difficulties with the hypothesis that the nuclear envelope can sustain persistent calcium gradients. Studies of the permeability of the nuclear envelope reveal that hydrophilic compounds under $20 \mathrm{kDa}$ can freely diffuse into the nucleus (Horowitz, 1972; Century and Horowitz, 1974; Paine et al., 1975, 1981; Peters, 1984; Lang et al., 1986; reviewed in Peters, 1986). The nuclear pores that span the envelope can transport specific proteins, up to $149 \mathrm{kDa}$ in size, into the nucleus. While this active transport is required for molecules greater than 70 $\mathrm{kDa}$, smaller molecules are able to diffuse through the pores even when active transport is blocked by compounds such as wheat germ agglutinin that bind to pore proteins (Dingwall and Laskey, 1986; Finlay et al., 1987; Finlay and Forbes, 1990; Hinshaw et al., 1992; Moore and Blobel, 1992). This literature suggests that the resistance of individual pores is no greater than that of the cytoplasm. Any attempts to generate a persistent N/C calcium gradient, for example, via a calcium-ATPase, should be short circuited by the free diffusion of calcium through the pores, assuming that the pores are present at a sufficiently high density (Dingwall and Laskey, 1986). One approach to resolving the opposing views of the permeability of the neuronal nuclear envelope is to apply the optical sectioning ability of the confocal microscope to the study of $\mathrm{N} / \mathrm{C}$ calcium gradients in cultured ncurons.

The permeability of the nuclear envelope is of interest because calcium is likely to regulate gene expression through a variety of calcium binding proteins such as protein kinase $\mathrm{C}(\mathrm{PKC})$ and calmodulin (Greenberg et al., 1986; Szekely et al., 1990; Murphy et al., 1991; reviewed by Ginty et al., 1992; Bading et al., 1993). Because these proteins are constitutively present in the nucleus (Bachs et al., 1992; Matter et al., 1993), any gating of calcium by the nuclear envelope could potentially modulate gene expression. Calcium might act more directly by activating a "calcium response element" found in neurons and other cell types (Rodland et al., 1990, 1992; Sheng et al., 1990; Pribnow et al., 1992). Nuclear calcium may also participate in pathological processes such as ischemia (Choi, 1987, 1992; Nitsch and Frotscher, 1992), epilepsy (Duman et al., 1992), and Alzheimers's disease (Mattson et al., 1992, 1993). Pathological effects of calcium include activation of proteases such as calpain, which is coactivated by DNA and micromolar calcium (Mellgren et al., 1993), and activation of endonucleases that are implicated in cell death (McConkey et al., 1989; Bartlett et al., 1992; Dowd et al., 1992; Joseph et al., 1993).

Other evidence suggests that calcium may be directly released into the nucleus. The inner and outer membranes of the nuclear envelope enclose the perinuclear space, and a calcium-ATPase pumps calcium into this space (Nicotera et al., 1989, 1990; Lanini et al., 1992). The presence of free calcium in this space is suggested by a fura 2 study showing perinuclear rings in saponin-permeabilized cells (Glennon et al., 1992). The presence of inositol trisphosphate and ryanodine receptors in the nuclear membranes of neurons (Ross et al., 1989; Walton et al., 1991) and other cell types (Malviya et al., 1990; Matter et al., 1993) and the exclusive presence of a subtype of phosphoinositidase in the nuclear membrane (Mazzoni et al, 1992) suggest that this store of calcium may be specifically activated. The permeability of the nuclear pore will affect both the spread of cytosolic calcium signals into the nucleus as well as the maintenance of calcium increases that might be generated inside of the nucleus.

The laser-scanning confocal microscope provides excellent temporal and spatial resolution for studying ncuronal calcium gradients (Hernandez-Cruz et al., 1990; Holliday et al., 1991). Here, for example, increases in nuclear calcium are observed after brief $(5 \mathrm{msec})$ depolarizations or even single action potentials. The calcium indicator fluo 3 complements confocal microscopy because of its sensitivity and dynamic range (Minta et al., 1989; Segal and Manor, 1992; van den Pol et al., 1992). But to take advantage of fluo 3 (and other single wavelength indicators) a problem must be resolved-a problem that is very closely related to the gradient problem discussed earlier. In cells filled with fluo 3 (salt form), the nucleus is invariably brighter than the cytoplasm. Is this additional fluorescence due to increased nuclear fluo 3, or is it due to increased calcium in the nucleus? To address this problem, the technique of internal perfusion of whole-cell patch pipettes was used together with measurement of confocal volumes so as to calibrate independently nuclear and cytosolic fluorescence signals. This calibration suggests that persistent $\mathrm{N} / \mathrm{C}$ gradients are not present in cultured sympathetic neurons. Rapid-imaging experiments that visualize the diffusion of calcium into the nucleus support this conclusion.

A portion of this work has been published in abstract form (O'Malley et al., 1993).

\section{Materials and Methods}

Cell culture. Sympathetic neurons from the 8th, 9th, and 10th ganglia of adult bullfrogs were isolated, dissociated and maintained in primary culture as described previously (Kuffler and Sejnowski, 1983; see Marrion et al., 1991). The cells were cultured on Cell-Tak (Collaborative Medical Products)-coated glass coverslips $(0.17 \mathrm{~mm}$ thick), which formed the bottom of a well, cut out of a plastic $35 \mathrm{~mm}$ petri dish. These dishes were mounted on the stage of a Zeiss IM 35 microscope and superfused at room temperature with a modified bullfrog Ringer's intended to block sodium and potassium conductances, so that calcium currents could be recorded. The composition of the Ringer's was $95 \mathrm{~mm}$ sodium chloride, $2.5 \mathrm{~mm}$ potassium chloride, $5 \mathrm{~mm}$ HEPES-sodium, $1 \mathrm{~mm}$ magnesium chloride, $2 \mathrm{mM}$ calcium chloride, and $20 \mathrm{~mm}$ tetraethylammonium (TEA) chloride, pH 7.3 with $\mathrm{HCl} ; 10 \mathrm{~mm}$ glucose and $2 \mu \mathrm{M}$ tetrodotoxin were added to the Ringer's on the day of the experiment.

Electrophysiology. Whole-cell patch-clamp recordings were obtained using fire-polished pipettes pulled on a two-stage vertical Narishige puller; $1-5 \mathrm{M} \Omega$ resistances were measured using an intracellular solution designed for recording of calcium currents: $110 \mathrm{~mm}$ cesium chloride, $20 \mathrm{~mm}$ tetraethylammonium chloride, $5 \mathrm{~mm}$ HEPES-sodium, $1 \mathrm{~mm}$ magnesium chloride, $1 \mathrm{mM}$ ATP, and $100 \mu \mathrm{M}$ fluo 3 pentapotassium salt (Molecular Probes), pH 7.3 with $\mathrm{CsOH}$. In some experiments, BCECF, BCECF-dextran-10K, indo 1, rhod 2, and calcium green dextran (all from Molecular Prohes) were used in place of fluo 3. The free calcium concentration, based on the buffering of fluo 3 and contaminating calcium levels, was estimated at $100-170 \mathrm{~nm}$. This pipette concentration of free calcium is somewhat higher than levels rcported for 
these cells (Marrion and Adams, 1992; Nohmi et al., 1992), but cellular calcium is not effectively buffered by this recording solution. For "calcium clamp" experiments, $10 \mathrm{mM}$ BAPTA was included in the intracellular solution, cesium chloride was reduced to $90 \mathrm{mM}$, and appropriate amounts of calcium chloride (see below) were added to set free calcium levels. Whole-cell recordings with input resistances of 100-500 $\mathrm{M} \Omega$ were routinely obtained. Holding current and calcium currents were recorded on a Gould chart recorder and also photographed from a Tektronix storage oscilloscope. Cells were held at $-70 \mathrm{mV}$ using currents of $-1.0 \mathrm{nA}$ or less; dialysis of cells with $\mathrm{CsCl}$ necessitated the use of negative holding currents. This holding current may load fluo 3 into cells to levels above those resulting from passive diffusion. Peak calcium currents of $0.5-3.0 \mathrm{nA}$ were routinely observed; the relative stability of these currents was monitored as a mcasurc of the hcalth of the ccll. In some experiments action potentials were recorded using an intracellular solution containing $100 \mathrm{~mm}$ potassium methylsulfate, $20 \mathrm{mM} \mathrm{KCl}, 5$ mM NaCl, 5 mm HEPES-sodium, 3 mM $\mathrm{MgCl}_{2}, 2 \mathrm{~mm}$ ATP, and 100 $\mu_{\mathrm{M}}$ fluo 3; in these experiments the extracellular solution contained 4 mM CaCl${ }_{2}$, TEA chloride was replaced by $\mathrm{NaCl}$, and TTX was omitted.

Calcium determinations. The amount of calcium required to adjust free calcium levels (in solution containing $10 \mathrm{~mm}$ BAPTA) was calculated based on the methods of Fabiato and Fabiato (1979) using an iterative program written in the ASYST program language by Alvaro Villaroel. The accuracy of this program was verified by comparing its output with that of similar programs and with sample calculations performed manually. The buffering effects of the BAPTA, fluo 3, and ATP and the binding of magnesium and calcium are taken into account by this program. The dissociation constant $\left(K_{d}\right)$ of BAPTA for our osmolarity and temperature was taken to be $150 \mathrm{~nm}$ : Tsien's (1980) value (110 nM) was corrected for osmolarity bascd on the observations of Harrison and Bers (1987). The $K_{d}$ of fluo 3 was taken to be $400 \mathrm{~nm}$ (Minta et al., 1989), although this value may increase substantially inside cells (see Results).

A calibration curve was produced by setting free calcium at a wide range of values, in droplets of intracellular solution, and then measuring the fluorescence of fluo 3 (see Fig. $5 \mathrm{~A}$ ). A predicted fluorescence value was determined by calculating the fraction of fluo 3 bound to calcium and multiplying this fraction by the observed maximal fluorescence increase observed experimentally (53-fold) upon going from calciumfree fluo 3 to fully calcium-bound fluo 3 . In $F_{p}=[(100-B)+53 * B]$ - $S, F_{p}$ is the predicted fluorescence, $B$ is percentage of fluo 3 that is calcium bound, and $S$ is the scaling factor used to convert this arbitrary number to the gray scale obtained for the experimental data. The first term in the equation represents the fluorescence of calcium-free fluo 3. This approach is functionally equivalent to the approach of Kao et al. (1989), except that their explicit solution is replaced by the output of the ASYST program.

The $K_{d}$ values used for BAPTA and fluo 3 produce a reasonable fit between predicted fluorescence and the fluorescence observed experimentally in protein-free recording solution (see Fig. $5 A$ ). Other dissociation constants could be used in these calculations. Harrison and Ber's (1987) $K_{d}$ for BAPTA is $230 \mathrm{nM}$ for our experimental conditions. Molecular Probes has recently published a $K_{d}$ of $320 \mathrm{nM}$ for fluo 3 (Haugland, 1992). While these values would alter calculated free calcium levels, use of these alternate values does not materially affect my conclusions.

Confocal microscopy. Calcium imaging was performed on an inverted Zeiss IM 35 microscope with the Bio-Rad MRC 600 laser-scanning confocal imaging system, using a Leitz $50 \times, 1.0 \mathrm{NA}$ water-immersion objective. Fluo 3-filled cells (or calibration droplets) were illuminated by the $488 \mathrm{~nm}$ line of a $25 \mathrm{~mW}$ argon laser, that was usually attenuated with a $1 \%$ transmission neutral density filter. Although the dynamic range of the system is nominally 255 (8-bit gray scale), in practice, noise precludes accurate measurements near the upper and lower end of the gray scale. The experimental goals absolutely required the measurement of very low and very high fluorescence levels (e.g., autofluorescence/ early stages of filling vs well-filled cells with high calcium levels) that far exceeded even the nominal 255 gray level dynamic range. To make such a range of measurements, it was necessary to adjust the photomultiplier gain setting in some experiments, particularly those of Figure 5. Consequently, correction factors were determined to allow scaling of fluorescence measurements to a common scale.

Scaling factors were determined by measuring calibration solutions at a range of gain settings $(10.0,9.0,8.0$, and 7.0), using droplets with a range of fluorescent intensities (achieved by varying free calcium). A broad range of fluorescence levels was measured in the determination of each scaling factor. The system behaved nearly linearly at gray scale values between 20 and 220; at higher or lower values "clipping" of the signals distorted the measurement of average pixel intensities. The error bars in the calibration curve (see Fig. $5 A$ ) reflect the variance in the measurements madc on single droplcts using this range of gain settings. Each point represents four to eight measurements made using different gain settings and including two scan speeds as well $(\mathrm{F} 1=$ slow or $\mathrm{F} 2=$ fast). Scan speed changes were corrected for in the same way as gain changes. The adequacy of correction factors determined from droplets was confirmed by making multiple measurements of cellular autofluorescence and fluorescence from fluo 3-filled cells (unstimulated) and verifying that the predetermined correction factors correctly scaled valucs taken at different gains and speeds.

Two confocal aperture settings were used. From the 15 unit scale on the instrument, a wider aperture (open 7 units) was used to maximize signal in the early stages of dye-filling experiments and when measuring autofluorescence, while most measurements were made using a narrower aperture (open 4 units) to achieve a thinner optical section. A scaling factor to correct values from the wider to the narrower aperture was determined in the same manner as the scaling factors for gain and speed. While in theory it is not desirable to vary the instrument settings, these variations were the minimum necessary to obtain the experimental objectives. Thus, all fuorescence values in this article, including both droplet calibration and cellular responses, were scaled to a single standard instrument setting: gain $=10.0$, speed $=F 1$, box size 4 , and aperture $=7$ units open. In the color images presented, the fluorescence intensity values have been converted to a spectral color scale. Asymmetrical indicator distribution precludes generation of a simple "color- to-calcium" map. The color scale illustrates particular spatial and temporal features. Fluorescence (and calcium) levels are explicitly quantitated in subsequent figures.

In vivo optical section thickness (distance of half-maximal fluorescence) for the $50 \times$ objective was determined by measuring the intensity of small, highly autofluorescent pigment granules (about $0.5 \mu \mathrm{m}$ in diameter) while changing the plane of focus-referred to as an " $x z$ " scan. Pigment granules located near the middle of cells were chosen so as to best reflect the optical conditions used in measuring cellular calcium signals. For the aperture $=7$ setting, optical section thickness was 3.2 $\mu \mathrm{m}$, and for the aperture $=4$ setting, it was about $1.7 \mu \mathrm{m}$. Optical section thickness values obtained using $0.2 \mu \mathrm{m}$ fluorescent beads were in rough agreement with these values. When measuring nuclear fluorescence, the objective was focused at the center of the nucleus along the $\mathrm{z}$-axis.

Rapid imaging. Frame (or linescan) acquisitions were synchronized with voltage pulses using a TTL pulse from a World Precision Instruments interval generator. The timing of image acquisition was monitored with the scan-active output of the MRC 600 using a Tektronix storage oscilloscope. The voltage-command pulse used to stimulate calcium influx was simultaneously displayed on the oscilloscope. This allowed the voltage pulse to be positioned at a particular point during the acquisition of images. The timing was recorded photographically during experiments. A zoom factor of 4.0 was typically used together with a display frame size of about $100 \times 70$ pixels. This allowed rapid acquisition of 35 successive frames into the frame buffer $(768 \times 512$ pixels), and provided the desired degree of spatial and temporal resolution. Averaging of multiple stimuli was done by accumulating one to four additional trials (scaled) into the frame buffer using the Bio-Rad accumulative filter. Intertrial intervals of $45-90 \mathrm{sec}$ were used, with the shorter intervals used for briefer stimuli where recovery to resting calcium levels was faster. Longer intertrial intervals would be complicated by the gradual increase in fluorescence that continues even after 15 or more minutes of filling as seen here (see Figs. 5, 7, 8) and observed by others after filling for $8 \mathrm{~min}$ or more in much smaller cells (Pusch and Neher, 1988; Fig. 11 of Neher and Augustine, 1992).

Internal perfusion. Internal perfusion of the patch pipette was performed by running a small quartz tube (fused silica capillary tubing, Polymicro Technologies) down the inside of the patch pipette. The outer diameter of the quartz tube, initially $190 \mu \mathrm{m}$, was drawn to $145 \mu \mathrm{m}$ using a butane torch. The back of the quartz tube was fit inside propylene tubing that ran to a reservoir containing the next solution to be used. This line is clamped closed during the initial patching and recording period. Upon opening the valve, the residual negative pressure (applied during seal formation) causes the solution from the reservoir to flow through the line into the pipette tip. Some additional negative pressure is often required to initiate and maintain flow. The technique of internal 


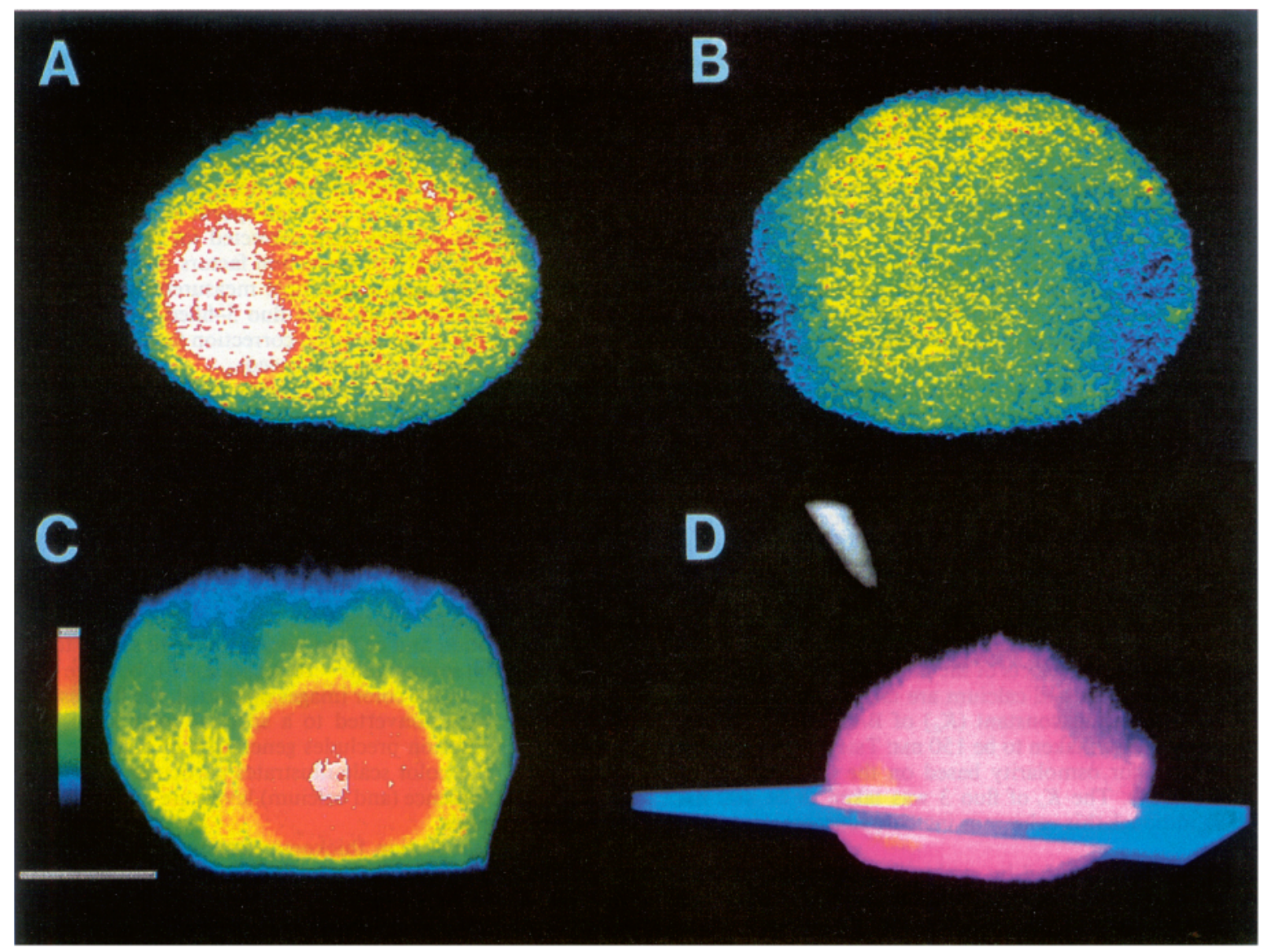

Figure 1. Nuclear and cytosolic confocal volumes. $A$ and $B$, Two optical sections, $11 \mu \mathrm{m}$ apart, taken 30 min after patch clamping cell. Cell was filled with $100 \mu \mathrm{M}$ fluo 3 and had been intermittently stimulated. Nucleus is evident only in lower frame $(A)$. The cell is dimmer in $B$, perhaps because of screening of exciting/emitting light by granular structures. $C$, "xz" scan of a cell filled with $250 \mathrm{nM}$ free calcium and $100 \mu \mathrm{M}$ fluo 3 . A line that crossed the nucleus was repeatedly scanned while the objective $(50 \times)$ was moved downward in $0.8 \mu \mathrm{m}$ steps. $D$, Three-dimensional representation of 70 optical sections from the cell shown in $A$ and $B$. This transparent rendering was generated on a Silicon Graphics workstation by R. Avila and L. Sobierajski using custom software (Avila et al., 1992). The blue platform is the thickness of a 3.2- $\mu \mathrm{m}$-wide optical section corresponding to the wider of the two confocal aperture settings used in this series of experiments. In these cultured neurons, the z-height of the nucleus ranged from 5 to 10 times the optical section thickness. Scale bar for $A-C$ is $15 \mu \mathrm{m}$ and is positioned at the level of the coverslip in $C$. Color bar indicates relative fluorescent intensity in this and subsequent images.

perfusion and details of pipette geometry are described more fully in other work performed in the lab of Paul Adams (Lopez, 1992; Yu et al., 1994).

\section{Results}

\section{Calcium dynamics and optical sectioning of the neuronal} nucleus

Two optical sections, $11 \mu \mathrm{m}$ apart, are shown from a cultured sympathetic neuron loaded with fluo 3 by whole-cell patch clamping (Fig. 1 $A, B$ ). The nucleus is clearly delimited in the section closest to the coverslip $(A)$. In the upper optical section $(B)$, dark regions are evident near the edges of the cell. Dark regions were caused by organelles or pigmented granules that either excluded fluo 3 or screened fluorescent emissions; such regions were avoided in this study. Figure $1 C$ shows an "XZ" scan of another cell: a single line is scanned, the microscope objective is moved down $0.8 \mu \mathrm{m}$ and the process repeated until the entire depth of the cell is scanned. The optical section thickness $(2-3 \mu \mathrm{m})$ is a small fraction of the depth of the nucleus, and can be appreciated by noting the definition of the nucleolus. Figure $1 D$ is a three-dimensional rendering of a stack of optical sections from the cell shown in $A$ and $B$; the blue platform is the thickness of a 3- $\mu$ m-thick optical section. When the objective is focused at the center of the nucleus, nearly all $(>98 \%)$ of the signal obtained from a "confocal volume" measured in the nucleus originates from the nucleus - a key result for obtaining independent nuclear and cytosolic signals.

Diffusion of calcium through the nucleus is illustrated in Figure 2 . The only calcium buffer in the pipette is $100 \mu \mathrm{M}$ fluo 3 . Between images 1 and 2, the cell is depolarized for $50 \mathrm{msec}$, from -70 to $0 \mathrm{mV}$, which maximally activates the calcium current in these cells. The images are unprocessed except that they are an average of three identical stimuli triggered at $75 \mathrm{sec}$ intervals. The most prominent feature in image 2 is the ring of calcium influx under the membrane. Images were acquired at $200 \mathrm{msec}$ intervals, including $80 \mathrm{msec}$ of "dead time" in between scans. Hence, the cell "ages" by $120 \mathrm{msec}$ during the acquisition of each image. This is evident in image 2 , where the calcium "ring" has widened and fallen in intensity at the bottom of the image.

At the point in image 3 where the increase in nuclear calcium is evident, about $280 \mathrm{msec}$ had elapsed since the voltage pulse. Calcium diffusion in the nucleus and cytoplasm proceeds in parallel. A rather slight retardation of the entry of calcium into 


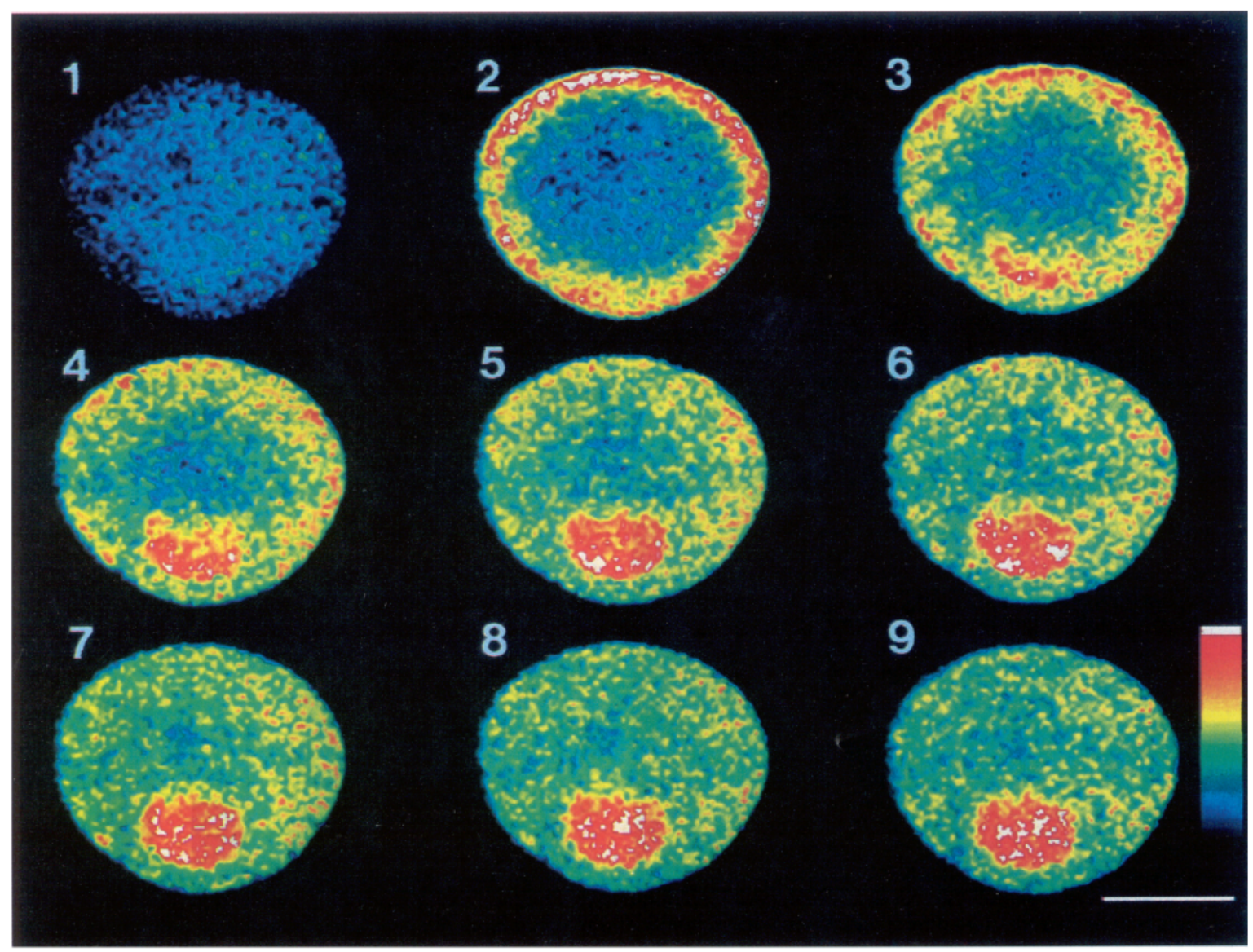

Figure 2. Apparent nuclear/cytosolic calcium gradient generated by a $50 \mathrm{msec}$ depolarization; 35 images were collected at $200 \mathrm{msec}$ intervals, from which a sequence of nine images are shown. Each image takes $120 \mathrm{msec}$ to acquire and is followed by $80 \mathrm{msec}$ of "dead time." The stimulus, a $50 \mathrm{msec}$ depolarization, ended just prior to the acquisition of image 2 . These images are an average of three successive stimuli acquired at 75 sec intervals. The calcium current was identical in the three stimuli. The fluorescence did not fully return to baseline in part because the cell was still filling with fluo 3 . Nonetheless, there was sufficient recovery after each stimulation, that the average fluorescence before stimulation was much lower than after stimulation. Scale bar, $20 \mu \mathrm{m}$.

the nucleus is suggested by the crescent-shaped increase in calcium along the edges of the nucleus. Were the rate of diffusion of calcium through the cell much greater than entry into the nucleus, the nucleus would appear as a uniform disk with a fluorescent intensity changing on a slower time scale than the cytoplasm. The most striking observation is the large increase in nuclear fluorescence relative to the cytoplasmic signal. Before considering the existence of amplified nuclear calcium signals, the contribution of autofluorescence must be taken into account.

The top two images in Figure 3 (same cell as Fig. 2) were taken before patching onto the cell. In the bright-field-like image (Fig. $3 A$ ), the nucleus and nucleolus are evident, while Figure $3 B$ shows prominent autofluorescence in the cytoplasm. The $50 \times$ water objective used is more efficient than other microscope objectives tested; autofluorescence was significant in spite of a $99 \%$ attenuation of the laser beam. Figure $3 C$ shows the fluorescence of the cell at $8 \mathrm{~min}$ after patching, just prior to collecting the data in Figure 2. While total fluorescence in the cell was relatively uniform, the nuclear signal is mostly fluo 3 , versus about half of the cytoplasmic signal (Fig. $3 D$ ). In every cell, out of 223 cells loaded with fluo 3 via patch pipette, the fluorescence of fluo 3 in the nucleus exceeded that in the cytosol.

In preliminary experiments (as in the very first such studies, performed here by Hernandez-Cruz et al., 1990), cells were imaged with a $40 \times, 0.75 \mathrm{NA}$ objective through the bottom of a petri dish, rather than a glass coverslip. The performance of this arrangement is indicated by the line in Figure $3 D$, which represents the signals measured from cells of similar autofluorescent intensity. With this optical arrangement (less efficient optics and greater spherical aberration), the cytoplasmic autofluorescence was not prominent (at the laser attenuation used) and did not greatly exceed the "nuclear" autofluorescence. The effective result of this was a failure to measure a significant fraction of the nuclear fluo 3 in resting cells, that is, the fluorescence below the horizontal line. Because fluo 3's fluorescence can increase by more than 50 -fold after binding calcium, this "undetected" nuclear dye can produce, in stimulated cells, a large signal and an apparent nuclear amplification.

Figure 4 shows the time course of calcium signals from the experiment in Figure 2; the entire experiment consisted of 35 frames acquired over $7 \mathrm{sec}$. Figure $4 A$ shows the regions of the cell where average fluorescence was quantitated. The raw data (average pixel intensity, Fig. $4 B$ ) and the same data after subtraction of autofluorescence (Fig. $4 C$ ) are shown. When the fluo 3 signals from the different compartments are normalized, the largest signals occur near the membrane of the cell while the peak signals in the nucleus and the cell interior are much smaller (Fig. 4D). Normalization is appropriate only if one assumes that, 

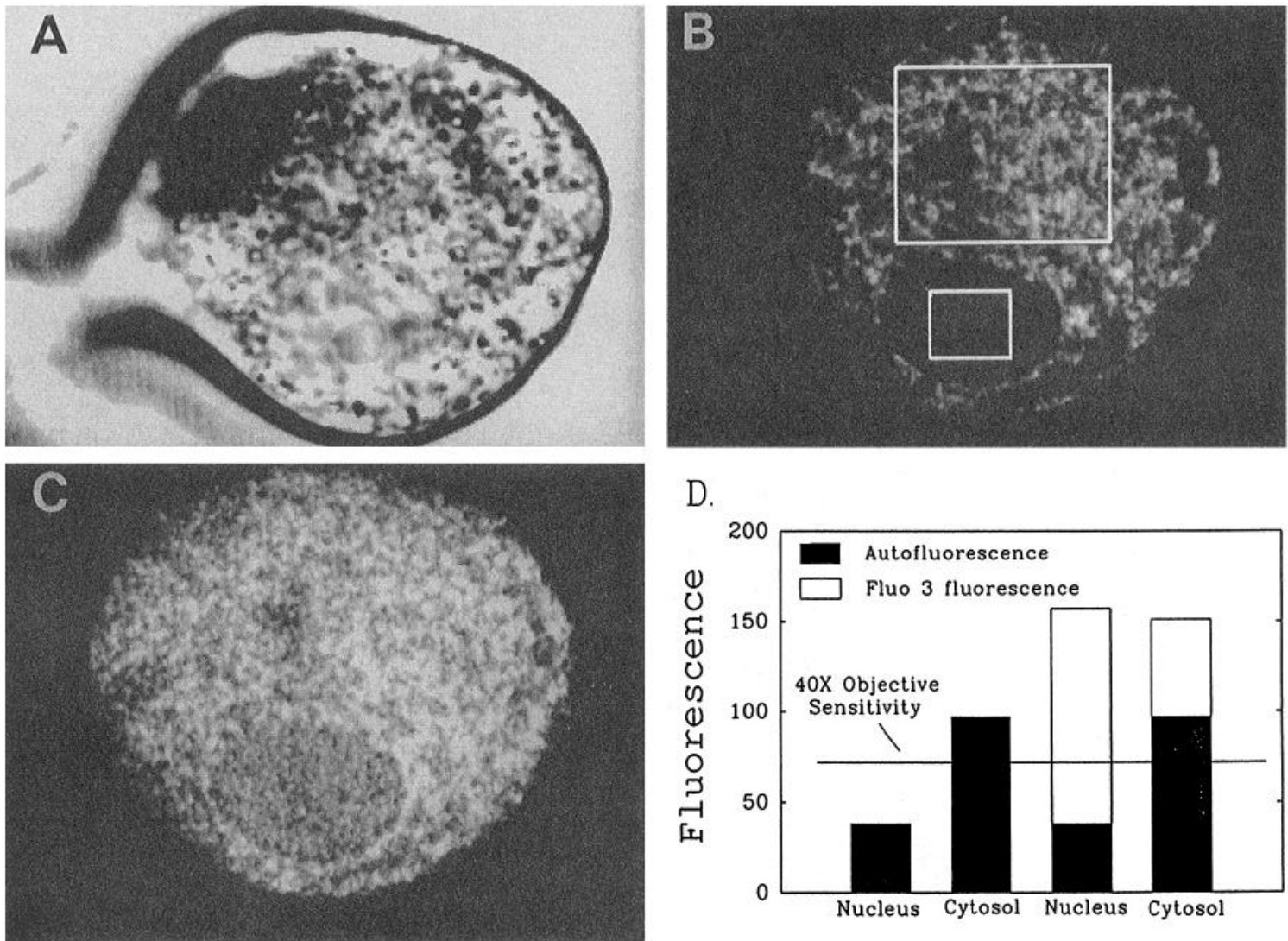

Figure 3. Contribution of autofluorescence to calcium images. A, This bright-field-like image (same cell as in Fig. 2) shows the nucleus and nucleolus, as well as dark pigment granules. The axon exiting from the left is above the plane of focus and does not appear in the confocal optical sections. $B$, Image of cellular autofluorescence taken prior to patching onto cell. Cytoplasmic autofluorescence is prominent. $C$, Image taken 8 min after patching onto cell, 2 min before the experiment in Figure 2. Fluo 3 fluorescence has "filled in" the nucleus and filled in between patches of cytoplasmic autofluorescence. The nuclear fluo 3 fluorescence is about equal to the total cytoplasmic fluorescence at this early stage of filling. $D$, Performance of different optical arrangements. The autofluorescence and fluo 3 fluorescence (average pixel intensity) in the nucleus and cytosol as observed with the $50 \times 1.0 \mathrm{NA}$ objective in $B$ and $C$ are shown graphically. The fluorescence above the horizontal line represents the performance obtained when viewing cells through a plastic petri dish with a $40 \times, 0.75$ NA objective, as done in earlier experiments, using cells of comparable autofluorescence and the same instrument settings; cytoplasmic autofluorescence modestly exceeded background fluorescence/dark current, while nuclear autofluorescence was not detected.

at rest, free calcium is uniform throughout the nucleoplasm and cytoplasm. With this assumption, the magnitude and time course of the calcium flux through the different compartments are consistent with passive diffusion models (Sala and Hernandez-Cruz, 1990). However, one might argue the converse: that gradients of free calcium can be maintained across the nuclear envelope and the greater resting fluorescence and fluorescence increase in the nucleus are due to a mechanism that maintains a resting gradient and then detects and amplifies cytoplasmic calcium signals.

\section{Calibration of nuclear and cytosolic fluo 3 signals}

To address this issue, independent calibrations were made for the nuclear and cytosolic signals. First, the behavior of fluo 3 in droplets of recording solution was measured (Fig. $5 \mathrm{~A}$ ); 10 mM BAPTA was used to set free calcium to desired levels, with appropriate amounts of calcium chloride added (see Materials and Methods). The predicted fluorescence, calculated from the predicted fraction of fluo 3 that is calcium bound, agrees reasonably well with the observed fluorescence. To calibrate fluo 3 signals inside cells, cells were loaded with $10 \mathrm{~mm}$ BAPTA and different levels of free calcium; autofluorescence is subtracted from all quantitative data shown here and below.
Figure $5 B$ shows a cell filled with $250 \mathrm{~nm}$ free calcium. The dashed line indicates the fluorescence of a $250 \mathrm{~nm}$ test droplet. The fluo 3 fluorescence shows a gradual, parallel increase in the nucleus and cytosol. While most cells approached a plateau, absolute plateaus were not observed, suggesting the presence of slow, ongoing processes such as dialysis, compartmentalization, or binding of fluo 3 (see, e.g., discussion in Pusch and Neher, 1988). This phenomenon was independent of calcium concentration and occurred in both cytosol and nucleus (Fig. $5 C, D$ ). Cellular fluorescence was correlated with the pipette calcium level, particularly at later time points. The effects of photobleaching (P) appeared to be minimal at the illumination intensity used-fluo 3 inside the cell remained sensitive to calcium increases after acquisition of many images (L). The degree of calcium buffering is indicated by the small size of the response to a series of short depolarizations (S); this train of stimuli produced an aggregate depolarization of $7200 \mathrm{msec}$, in contrast to the $50 \mathrm{msec}$ depolarization in Figure 2. Rapid imaging after single pulses in BAPTA-loaded cells showed no significant increase in calcium.

The key point of Figure 5 is that the nucleus and cytosol have separate calibration curves, with the nucleus being about 2.3fold brighter than the cytosol (note the difference in scale, Fig. 

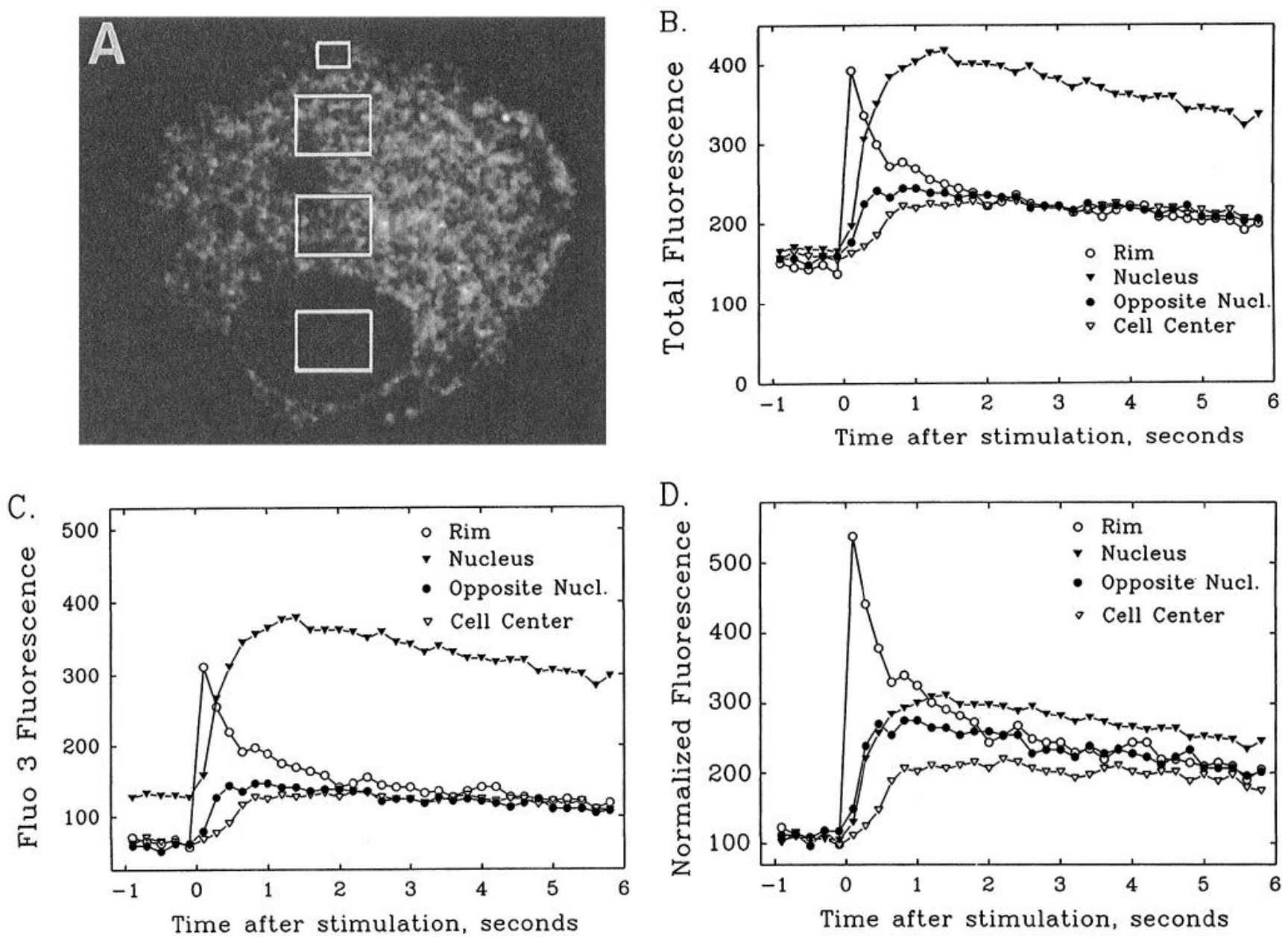

Figure 4. Time course of nuclear and cytosolic calcium changes. A, Measuring boxes show the regions of the cell analyzed (from Figs. 2, 3). B, The average pixel intensity for each region (Total Fluorescence) is plotted as a function of time. " 0 " time corresponds to the beginning of the 50 msec depolarization. $C$, Values from $B$ are replotted after subtracting the contribution of autofluorescence as measured in Figure 2. $D$, Responses in each region were normalized to the resting fluo 3 fluorescence (i.e., first five data points). If one assumes that the differences in resting fluorescence are due to an unequal distribution of fluo 3, then the largest response occurs at the edge of the cell, while responses in equivalent regions of the nucleus and cytoplasm are about equal. In other experiments, nuclear and cytosolic signals were imaged over a longer period. They decayed in parallel, with fluorescence returning $90 \%$ of the way to baseline over a period of $35 \mathrm{sec}$.

$5 C, D)$. This is not unexpected since a significant fraction of the cytosol is occupied by membrane-bound organelles that will exclude hydrophilic molecules (discussed in Peters, 1986). Figure 6 shows plots of the nuclear/cytoplasmic $(\mathrm{N} / \mathrm{C})$ fluorescence ratios of cells from Figure 5. There are two main trends. First, the N/C ratio is relatively independent of calcium concentration. If the fluorescence gradient were due to a persistent $\mathrm{N} / \mathrm{C}$ calcium gradient, then that gradient would have to be maintained independently of absolute calcium levels. The elevated and noisy ratios during the first few time points may be due to the initially small size of the cytoplasmic fluo 3 signal, which is partially obscured by the high level of cytoplasmic autofluorescence, although rapid entry of fluo 3 into a small compartment may contribute to this effect. The bar graph (Fig. $6 B$ ) summarizes the ratios obtained after $20 \mathrm{~min}$ of filling with different calcium levels, and also shows a ratio after loading with manganese.

A second observation is the gradual decline in the N/C ratio with time. This gradual decline occurs at all calcium concentrations (Fig. $6 \mathrm{~A}$ ) and may be due to slow internalization of fluo 3 into cytoplasmic organelles. Because organellar calcium is usually high, cytoplasmic fluorescence would be selectively in- creased, thereby decreasing the N/C ratio. This organelle-bound background would contribute relatively more fluorescence at low cellular calcium levels and would likely be insensitive to increases in calcium outside the organelles. This might explain why the N/C ratio increases a little when calcium is increased (Figs. 6B, 7B). Possible mechanisms of internalization include anion transporters, "reverse" functioning of intracellular esterases that normally cleave the ester linkages of membrane-permeant indicators, and direct permeation of fluo 3 through the lipid bilayer.

While these results indicate that the nucleus and cytoplasm have independent calibration curves, cell-to-cell variability might conceivably produce such a result. If at the highest calcium levels used, cytoplasmic free calcium was still well below the level needed to nearly saturate fluo 3 (i.e., well below $10 \mu \mathrm{M}$ ), then a $\mathrm{N} / \mathrm{C}$ calcium gradient could still account for the increased nuclear fluorescence. To address this, cells were first filled with 10 nм calcium. After the fluorescence approached a plateau, the patch pipette was internally perfused with high calcium $-10 \mu \mathrm{M}$ in Figure $7 A$. The fluorescence increased rapidly and dramatically. As before, fluorescence in the nucleus and cytosol rose 


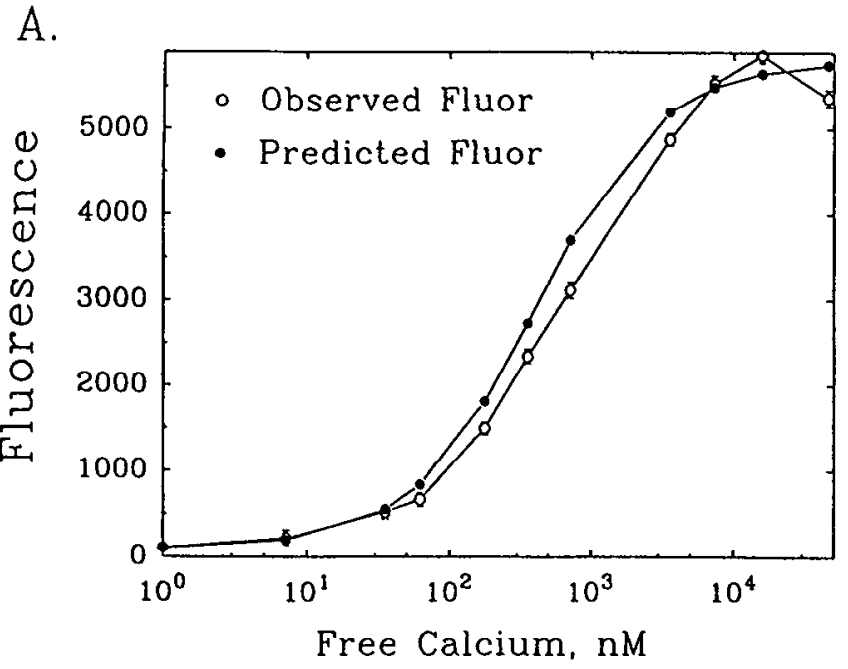

C.

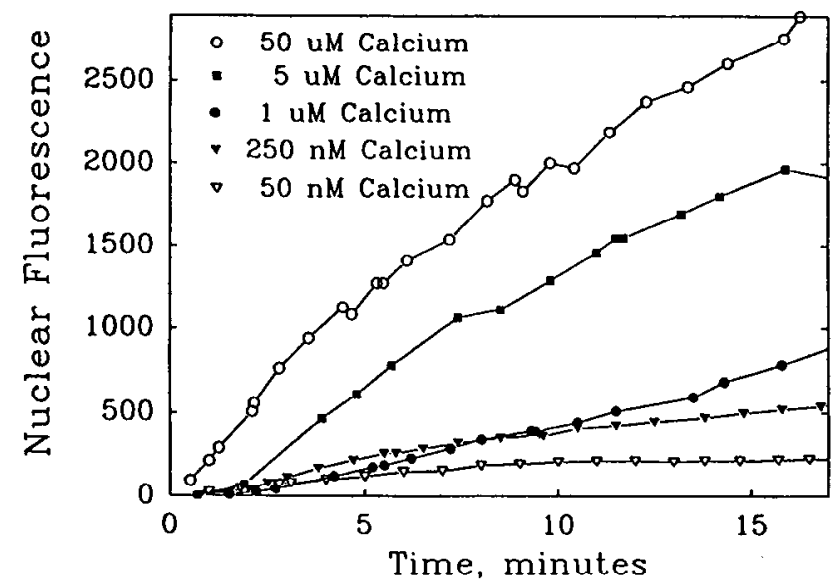

B.

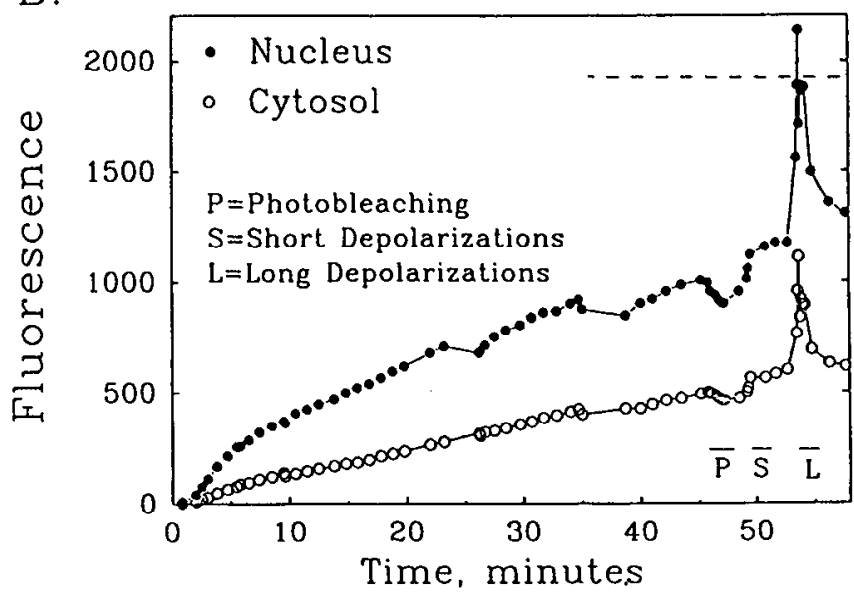

D.

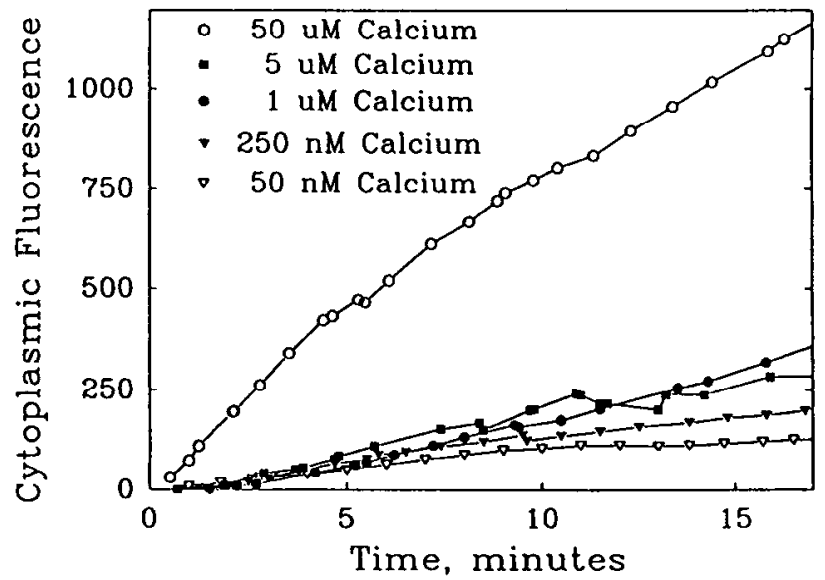

Figure 5. Effects of calcium on nuclear and cytoplasmic fluorescence. $A$, Behavior of fluo 3 in droplets of recording solution (100 $\mu \mathrm{M}$ fluo 3 , 10 mM BAPTA). Setting of free calcium levels and generation of the predicted fluorescence curve are described in Materials and Methods. $B$, Example of a cell loaded with $250 \mathrm{nM}$ free calcium in the pipette. Nuclear and cytosolic regions were analyzed as described in Figure 4; autofluorescence is subtracted from this and subsequent data. Photobleaching $(P)$ of fluo 3 during 160 scans made in rapid succession (speed F2, 99\% attenuation) was minimal. A typical experiment required $200-300$ scans. A 90 sec train of short $(S)$ depolarizations $(10 \mathrm{msec}$ each, $3 \mathrm{~Hz}$ ) produced a small increase in fluorescence, while a similar train of longer $(L)$ pulses $(200 \mathrm{msec}$ each, $3 \mathrm{~Hz}$ ) overwhelmed the buffering capacity of the BAPTA. The responsiveness to depolarization $(L)$ indicates that fluo 3 had not been saturated with calcium. Dashed line indicates fluorescence of a 250 nM droplet $(A)$. $C$, Summary of nuclear fluorescence for five cells. Cells were included that could be held at $-70 \mathrm{mV}$ with holding currents of less than $1 \mathrm{nA}$ for at least $15 \mathrm{~min}$. D. Summary of cytosolic fluorescence for the same cells. Note the difference in scale. Inspection of images from the cell filled with $5 \mu \mathrm{M}$ calcium revealed an extensive presence of pigment granules below the plane of focus in the cytoplasm; this would reduce the cytosolic fluorescence.

roughly in parallel, increasing 24 -fold in the nucleus and 18 fold in the cytoplasm. This is essentially the full dynamic range of fluo 3 in calibration droplets, where fluorescence increases 25 -fold when calcium is raised from $10 \mathrm{~nm}$ to saturation.

To retain the N/C calcium gradient hypothesis, one might propose that the dye in situ has a much larger dynamic range than in vitro. An expanded dynamic range would allow the cytoplasmic signal to increase 18 -fold and still be well below saturation (i.e., capable of increasing by more than $100 \%$ to equal the nuclear fluorescence). A different approach employs the interaction of manganese with fluo 3. Manganese binds 70fold more tightly to fluo 3 than does calcium $\left(K_{d}\right.$ for manganese $=6 \mathrm{nM}$ ) and manganese-fluo 3 is eightfold brighter than calcium-free fluo 3 (Minta et al., 1989). After loading a cell with $10 \mathrm{~nm}$ free calcium, the cell was subsequently perfused with 20
mM manganese (Fig. 7B). The fluorescence increased rapidly and substantially in both cytoplasm and nucleus, indicating that manganese readily permeates the nuclear envelope. A typical $\mathrm{N} / \mathrm{C}$ fluorescence ratio averaging about 2.3 was observed. Because free manganese in the pipette exceeds $10,000,000 \mathrm{nM}$, and fluo 3's $K_{d}$ for manganese is only $6 \mathrm{nM}$, it seems certain that virtually all of the fluo 3 in the cell is bound with manganese, eliminating divalent cation gradients as an explanation for the $\mathrm{N} / \mathrm{C}$ fluorescence difference. Bath-applied manganese had no obvious effects on these cells other than to abolish the calcium current.

The $K_{d}$ of calcium indicators is strongly influenced by the intracellular environment. This is true for fura 2 , indo 1 , fura red, and as shown recently in muscle, fuo 3 (Harkins et al., 1993; and see Discussion). In all cases, the $K_{d}$ increases upon 
binding to proteins, perhaps by as much as three- to fivefold inside cells. While this magnitude of an increase does not affect the interpretation of the manganese experiment, the $K_{d}$ of fluo 3 for calcium does seem increased inside cells. As shown in Figure $5, C$ and $D$, there is a large fluorescence increase when pipette calcium is raised from $5 \mu \mathrm{M}$ to $50 \mu \mathrm{M}$, while in the cuvette calibration, fluo 3 was nearly saturated at $5 \mu \mathrm{M}$. An increased intracellular $K_{d}$ for fluo 3 is also supported by the failure of cells filled with $250 \mathrm{~nm}$ calcium to reach the fluorescence level of 250 nM droplets. Similarly, in a cell loaded with $1 \mu \mathrm{M}$ free calcium, an intense depolarization caused a 2.2-fold fluorescence increase in nucleus and cytoplasm, indicating that the $K_{d}$ is greater than $1 \mu \mathrm{M}$. Incomplete buffering of calcium remains an issue, but if one assumes that buffering is adequate, then the $K_{d}$ of fluo 3 inside the cell appears to be roughly $2 \mu \mathrm{M}$, a value consistent with the findings of Harkins et al. (1993).

\section{Other indicators}

Another possible explanation for the excess nuclear fluorescence could be the existence of a $\mathrm{pH}$ gradient across the nuclear envelope, with a $\mathrm{pH}$ decrease being induced by calcium. To test this hypothesis, cells were loaded with the $\mathrm{pH}$ indicators $\mathrm{BCECF}$ or BCECF-dextran $\left(10,000 M_{r}\right)$. The fluorescence of a BCECFdextran loaded cell (Fig. 8A) decreases within $60 \mathrm{sec}$ after introduction of $20 \mathrm{~mm}$ sodium acctatc to the Ringer's $(41 \%$ dccrease in the nucleus, $56 \%$ in the cytosol). Other workers using BCECF (Uneyama et al., 1993) have, upon bath application of $20 \mathrm{~mm}$ sodium acetate, observed fluorescence decreases and a fall in $\mathrm{pH}$ from 7.2 to 6.8 . In other cells loaded with these same indicators, there was no significant change (less than $2 \%$ ) in either nuclear or cytosolic fluorescence in response to depolarizations that ranged from 50 to $5000 \mathrm{msec}$ and produced large calcium currents. In cells from the same batch that were loaded with fluo 3 , the longer pulses produced large (micromolar) increases in intracellular calcium that lasted for tens of seconds. Thus, substantial calcium loads failed to produce a detectable change in $\mathrm{pH}$ levels - had $\mathrm{pH}$ changed substantially enough to alter fluo 3's fluorescence (see Minta et al., 1989), it should have been detected.

These experiments further support the hypothesis of a greater amount of available aqueous space in the nucleus. The N/C fluorescence ratio (after background correction) was 2.1 and 1.6 for free BCECF and BCECF-dextran, respectively. Figure $8 C$ shows a cell loaded with calcium green dextran, while Figure $8 D$ shows a neuron loaded with rhod 2 . In these cases the resting $\mathrm{N} / \mathrm{C}$ fluorescence ratio ranged from 1.7- to 3.1-fold for calcium green-dextran $(n=3)$ and 5-6-fold for rhod $2(n=4)$. In the case of rhod 2, the nucleolus was extremely bright, an average of 14.9 times rhod 2's cytosolic fluorescence. Selective nucleolar labeling by rhod 2 was apparent from the outset even in cells that appeared quite healthy by electrophysiological measures. Stimulation caused similar fluorescence increases in cytoplasm, nucleus, and nucleolus in these cells. Specific nucleolar labeling was not observed with the other indicators with the exception of fluo 3-loaded cells that had been imaged and stimulated for long periods and were possibly in declining health (e.g., Fig. 1C). Taken together, these results indicate that while "available aqueous space" consistently plays a role in nuclear/cytosolic fluorescence differences, other interactions of activity indicators are likely to be important, perhaps requiring the same type of calibration as presented here for fluo 3 .
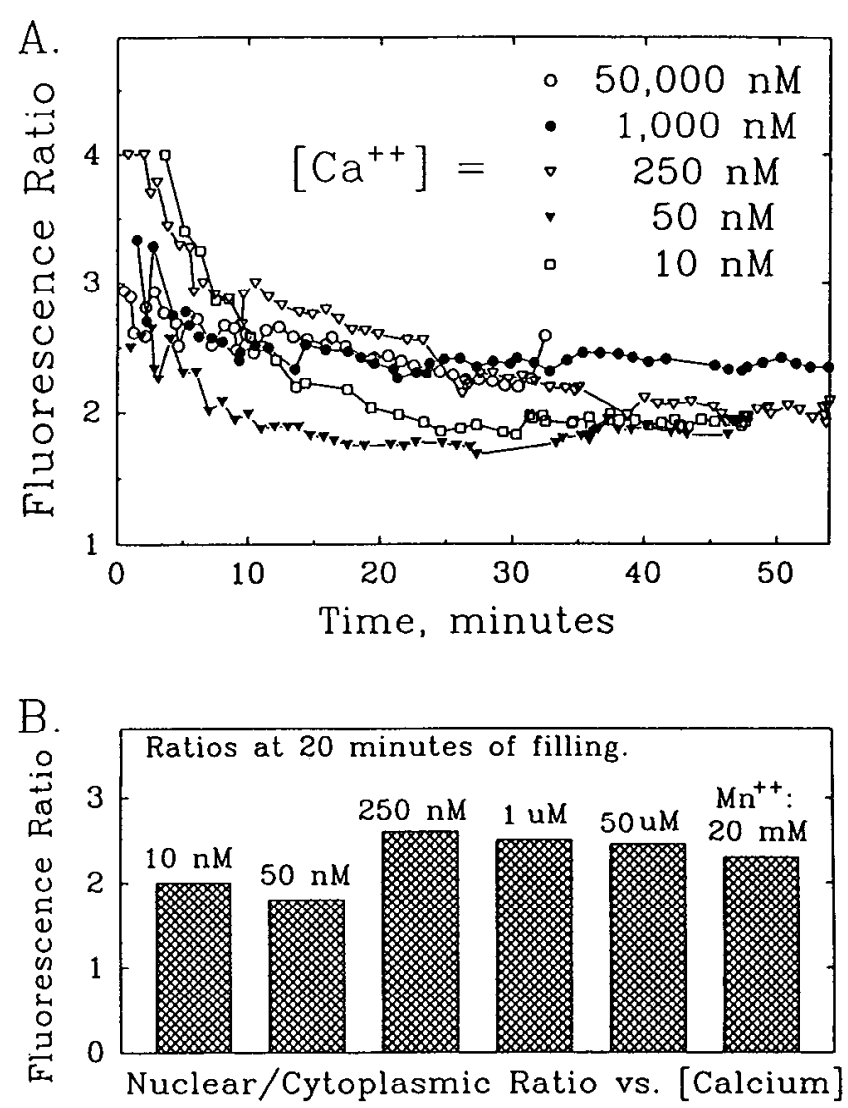

Figure 6. Nuclear/cytoplasmic (N/C) fluorescence ratios at different levels of free calcium. Data from cells shown in Figure 5, $C$ and $D$, were ratioed and plotted as a function of time. During the first few minutes of dye filling, the signal from cytoplasmic fluo 3 tends to be overwhelmed by cytoplasmic autofluorescence and may be affected by nonlinearity of the photomultiplier at low gray scale values (see Materials and Methods). This may explain the large, noisy ratios observed shortly after attaining the whole-cell recording configuration. The $\mathrm{N} / \mathrm{C}$ ratios tended to decline with time, perhaps because fluo 3 was gradually being incorporated into cytoplasmic organelles. This would affect $\mathrm{N} / \mathrm{C}$ ratios more at low calcium then at high calcium levels. $B, \mathrm{~N} / \mathrm{C}$ fluorescence ratios measured 20 min after formation of whole-cell recording configuration are shown. The ratio for manganese was obtained 5 min after initiating loading of manganese (see Fig. 8).

Reports showing N/C calcium gradients have often used membrane-permeant (AM, acetoxymethylester) calcium indicators. Cells loaded with fluo 3-AM showed a labeling pattern that was the reverse of patch-pipette-loaded cells (Fig. $8 E$ ). Upon patching onto such cells with pipettes lacking calcium indicator, these cells showed a gradual small decrease in fluorescence. Substantial depolarizations produced only small fluorescence increases ( $27 \%$ in the nucleus, $2 \%$ in the cytosol for the cell in Fig. $8 E$; no background correction). Upon subsequent perfusion of the patch pipette with the pentapotassium salt form of fluo 3 , the pattern of labeling reverted to the pattern that is always observed after patch pipette loading; the gain has been decreased and the fluorescence of the fluo 3 salt now predominates in both the nucleus and cytoplasm of this cell (Fig. $8 F$ ). Depolarization now produced large fluorescence increases $(118 \%$ in the nucleus, $73 \%$ in the cytosol). This result illustrates the potential extent of complications that may arise due to compartmentalization of AM indicators into the membranes or interior of cytoplasmic organelles. While much more useful loading is routinely attained 

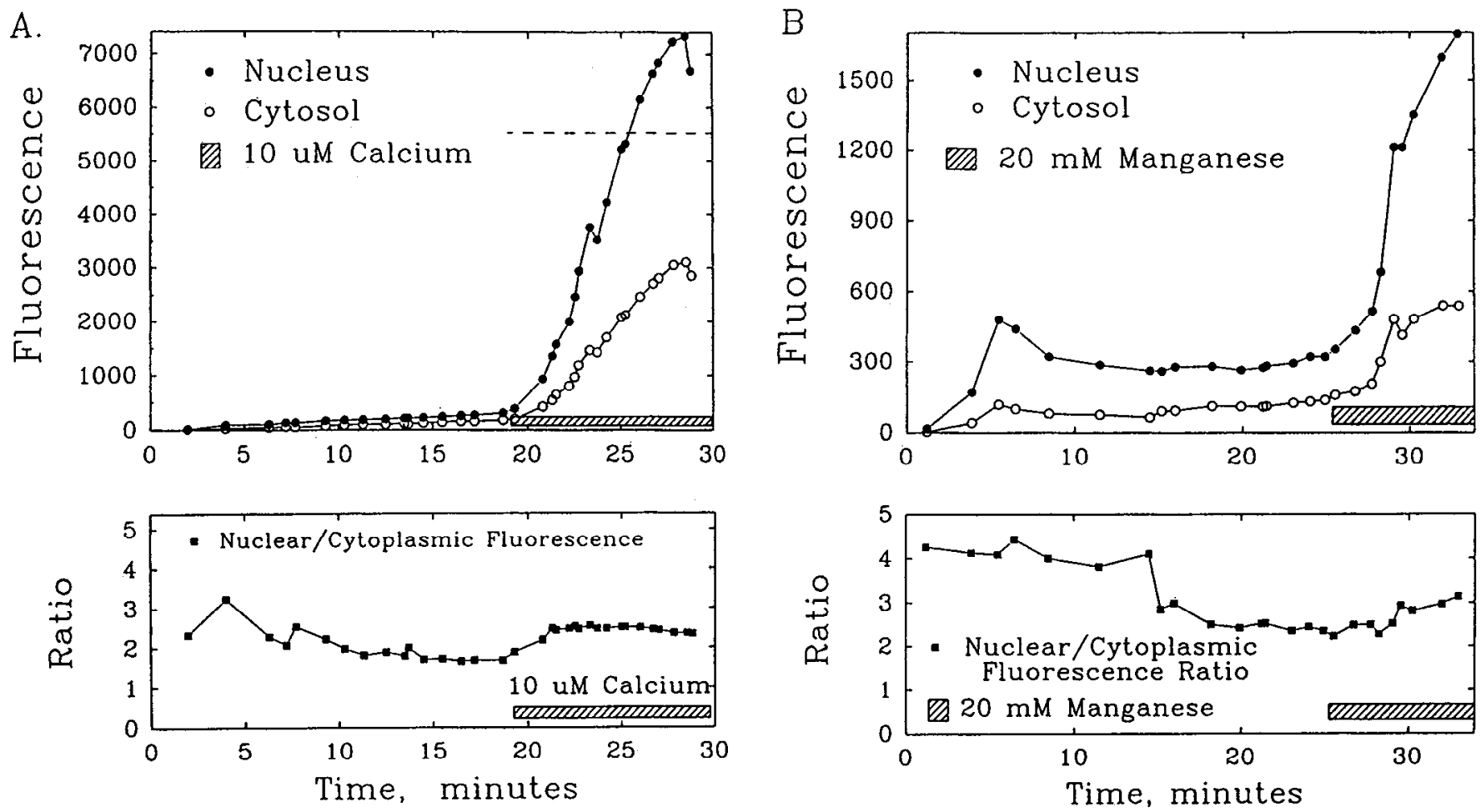

Figure 7. Calibration of nuclear and cytosolic signals with intracellular perfusion. $A$, Perfusion with high calcium. The cell was initially filled with free calcium set at $10 \mathrm{nM}$ (using $10 \mathrm{mM}$ BAPTA). After $18 \mathrm{~min}$ of filling, the patch-pipette was perfused with $10 \mu \mathrm{M}$ free calcium. Large, rapid fluorescence increases occurred in the nucleus (24-fold) and cytoplasm (18-fold). Dashed line, fluorescence of a droplet with $10 \mu \mathrm{M}$ free calcium. The lower panel shows a gradual decline in the $\mathrm{N} / \mathrm{C}$ ratio followed by a small increase during perfusion with $10 \mu \mathrm{M}$ calcium. For intracellular perfusion, lower-resistance pipettes (1-2 M $\Omega$ ) were used. $B$. Perfusion with manganese. Cell was filled for 25 min with 10 nM calcium. Early in the recording, the input resistance declined transiently; this coincided with a transient fluorescence increase, which then stabilized. Upon switching to $20 \mathrm{~mm}$ manganese, nuclear and cytoplasmic fluorescence increased rapidly and in parallel. Although the health of the cell (input resistance) gradually declined during perfusion with manganese, the bulk of the fluorescence increase occurred well before there was sufficient decline to generate calcium influx, based on experience in loading morc than 100 cells with fluo 3 . The fluorescence ratio (lower panel) showed the usual pattern of gradual decline followed by a small increase with increasing divalent cation concentration.

with AM indicators (e.g., Dani et al., 1992; Segal and Manor, 1992; van den Pol et al., 1992), it seems that pipette loading will permit the most accurate comparisons of nuclear and cytosolic signals.

\section{Delay and amplitude of nuclear signals}

The permeability of the nuclear envelope has significant implications for the calcium gradient hypothesis. The larger the permeability, the greater the energy demands on the cell for maintaining ionic or voltage gradients across the envelope. Confocal microscopy permits the "imaging" of a single line of interest at very high temporal ( $2 \mathrm{msec})$ and spatial $(2 \mu \mathrm{m}$ or less) resolution. Figure $9 A$ shows a line of interest selected in a cell filled with $100 \mu \mathrm{M}$ fluo 3 (no BAPTA). This line was scanned at $2 \mathrm{msec}$ intcrvals over the coursc of 1.1 scconds (Fig. $9 B$ ). At 170 mscc into the scan, the cell was depolarized for $100 \mathrm{msec}$. The influx of calcium into the cell is evident within $10 \mathrm{msec}$ after pulse onset. Within $80 \mathrm{msec}$, calcium begins entering the nucleus, that is, within as little as $10-20 \mathrm{msec}$ after the transient arrives at the nuclear envelope.

The rate of rise of calcium was monitored in two regions of the cell equidistant from the plasma membrane, one in the nucleus and the other in the cytoplasm. The average and background-subtracted fluorescence intensity is shown for each region (Figs. $9 C, D$ ). The normalized data show the nuclear signal beginning to rise in parallel with the cytoplasmic signal, although it plateaus about $200 \mathrm{msec}$ later (Fig. 9E). Fitting of exponentials to the fluorescence rise times in nuclear and cytosolic regions in three cells confirmed the existence of a "nuclear delay"- the average time constant was $128 \mathrm{msec}$ for the cytosol versus 229 msec for the nucleus. While this might be due to restriction of the diffusion path to the nuclear pores, Nohmi et al. (1992) suggested that calcium diffuses more slowly in the nucleus than in the cytosol.

One feature reported in several articles is an amplification by the nuclear envelope of cytosolic calcium signals (HernandezCruz et al., 1991; Przywara et al., 1991; Birch et al., 1992; Himpens et al., 1992a). If so, one possible mechanism would involve the cytosolic calcium signal reaching a threshold and generating an all-or-none nuclear response once the amplification mcchanism is activatcd. Nuclcar calcium signals wcre mcasured in response to depolarizations of different durations (Fig. 10). Responses were readily detected after voltage pulses as brief as $5 \mathrm{msec}$, and even after single action potentials. As the stimulus duration is increased, the responses grow incrementally larger. This is consistent with passive diffusion of calcium into the nucleus. A rough estimate of absolute calcium levels is shown. This estimate assumes a resting calcium of $100 \mathrm{~nm}$ and is provided only to suggest the magnitude of the nuclear responses (see Discussion). If resting calcium was higher, then the absolute magnitude of the nuclear responses would also be larger. 


\section{Discussion}

\section{Evidence against resting. nuclear/cytoplasmic $(N / C)$ calcium gradients}

Confocal optical sectioning permitted independent calibration of nuclear and cytosolic signals. When the optical section was centered in the middle of the nucleus of these rather large neurons, the signals measured from the nucleus and cytoplasm were essentially uncontaminated by one another (Fig. 1). This permitted comparison of nuclear and cytoplasmic fluorescence while changing free calcium levels over a broad range. High-efficiency optics facilitated the use of confocal volumes by permitting accurate measurement of autofluorescence and fluo 3 fluorescence (Fig. 3). As a whole, these data provided no support for the existence of stable calcium gradients across the nuclear envelope of cultured sympathetic neurons.

Suppose we propose the converse: that the nuclear fluorescence is twice cytoplasmic fluorescence because nuclear free calcium is twice as high as cytosolic free calcium (the concentration of fluo 3 being equal in both compartments). If so, then once calcium is increased enough to saturate fluo 3 in the nucleus, further calcium increases will have no effect on nuclear fluorescence but will continue to increase cytoplasmic fluorescence. Once the cytoplasmic dye is also saturated, nuclear and cytoplasmic fluorescence will be equal. Hence, over this range of calcium increase, the $\mathrm{N} / \mathrm{C}$ ratio should fall from its maximal value to a value of 1 . Similarly, if one argues that only half of the fluorescence gradient is due to a calcium gradient, then the fluorescence difference should fall from its maximum value to one-half of the maximum difference. This does not occurraising calcium to levels that should have saturated fluo 3 never produced a decrease in the fluorescence ratio.

One could argue that the highest calcium levels used did not saturate cytoplasmic fluo 3. However, once nuclear fluo 3 was saturated with calcium, further calcium increases should have caused at least some decline in the $\mathrm{N} / \mathrm{C}$ ratio, even if cytoplasmic fluo 3 did not fully saturate. Just the opposite was observedat the highest levels of free calcium ( $50 \mu \mathrm{M}$ in the pipette, well above a concentration that essentially saturates fluo 3 ), the N/C ratio tends to be slightly higher than ratios obtained at lower calcium levels. To explain this, one would have to argue that even with $50 \mu \mathrm{M}$ free calcium in the pipette, cytoplasmic calcium is far below saturation. Intracellular perfusion rules out this possibility. When calcium was raised from $10 \mathrm{nM}$ to $10 \mu \mathrm{M}$, fluo 3 's fluorescence increased over the full dynamic range observed in vilro. This supports the contention that with $10 \mu \mathrm{M}$ calcium in the pipette, cytoplasmic fluo 3 was either saturated or quite close to saturation.

This suggestion that the increased nuclear fluorescence is due to an increased amount of fluo 3 is supported by the manganese perfusion experiment. Manganese rapidly enters the nucleus and cytoplasm -in sufficient quantities to increase the fluorescence to levels expected for manganese-saturated fluo 3 (Kao et al., 1989; Minta et al., 1989). Because the concentration of manganese in the pipette is 50,000 times the concentration required to saturate fluo 3 , it seems certain that fluo 3 is saturated in both compartments. The constancy of the N/C ratio at all manganese and calcium levels tested indicates that free calcium equilibrates between the nucleus and cytoplasm under all these conditions.

There is a simple explanation that may account for some of the N/C fluorescence difference. Much of the cytoplasm is occupied by membrane-bound organelles, which exclude hydrophilic compounds (discussed in Peters, 1986; Neher and Augustine, 1992). The extent of this exclusion was studied by injecting radiolabeled compounds such as sucrose, inulin, and dextrans into cells and measuring their partitioning between cytoplasm and nucleus using ultra-low-temperature autoradiography (Horowitz, 1972; Horowitz and Moore, 1974; Paine et al., 1975). Typically, a twofold or greater concentration of these compounds is observed in the nucleus, relative to the cytoplasm. More recent studies using fluorescent dextrans arrive at the same conclusion and show that dextrans with molecular weights up to $17,000 \mathrm{Da}$ can rapidly cross the nuclear membrane (Peters, 1984, 1986; Lang et al., 1986). Increased nuclear fluorescence is also observed with the charged form of ratiometric dyes (Neylon et al., 1990; Christ et al., 1992; Glennon et al., 1992; Neher and Augustine, 1992).

Exclusion of fluo 3 from organelles is only one of several possible explanations for the increased nuclear fluorescence. The nuclear signal might be due, in part, to enhancement of fluo 3's fluorescence by the nuclear environment, for example, by binding to nuclear proteins or DNA. At high calcium levels, the nuclear signal exceeded the signal of fluo 3 in test droplets, suggesting that such binding or other interaction occurs (compare Figs. $5 A, 7 A$ ). Of course, binding to cytoplasmic constituents is also likely (Konishi et al., 1988; Hove-Madsen and Bers, 1992). While the nucleus is "filled" with DNA, histones, and other proteins, the cytoplasm is similarly "filled" with ribosomes, mRNA, and structural proteins. The expected exclusion of fluo 3 by cytoplasmic organelles thus seems to produce a "baseline" of N/C fluorescence difference, but the situation is certainly more complex. This is illustrated by the variation in $\mathrm{N} / \mathrm{C}$ ratios seen with different calcium and $\mathrm{pH}$ indicators (Fig. 8 ), and more dramatically by the fluorescence of rhod 2 in the nucleolus.

\section{Evaluation of nuclear permeability via rapid imaging}

The rapid imaging experiments pose a different type of evidence against sustained $\mathrm{N} / \mathrm{C}$ calcium gradients. Calcium levels rise quite quickly in the nucleus, indicating substantial permeability. The 2 msec temporal resolution of the linescan (Fig. 9) shows that calcium begins entering the nucleus in as little as 10-20 msec after arrival at the nuclear envelope. When a region of the nucleus is compared with a region of cytoplasm that is equidistant from the plasma membrane (Figs. 2, 9), calcium levels in the nucleus lag the cytosolic increases by about $100-200 \mathrm{msec}$. This analysis depends on the geometry. The assumption is made that calcium enters the measured regions by diffusing in from the nearby plasma membrane seen in the optical sections or from plasma membrane that is about the same distance away. Because the optical sections are thin relative to the thickness of the cell (Fig. 1D), and because of the cell's spherical to slightly elliptical shape, this assumption approximates the actual situation. Any deviations would tend to affect nuclear and cytoplasmic signals equally.

This rapid calcium entry poses problems for the $\mathrm{N} / \mathrm{C}$ calcium gradient hypothesis. In order for a membrane to sustain ionic gradients, the membrane should be relatively impermeant to those ions. Instead, the nuclear membrane of these cells is rapidly traversed by both manganese, calcium, and larger molecules such as the 10,000 $M_{r}$ dextran forms of BCECF and calcium green (Figs. 7, 8), in agreement with the nuclear-pore perme- 

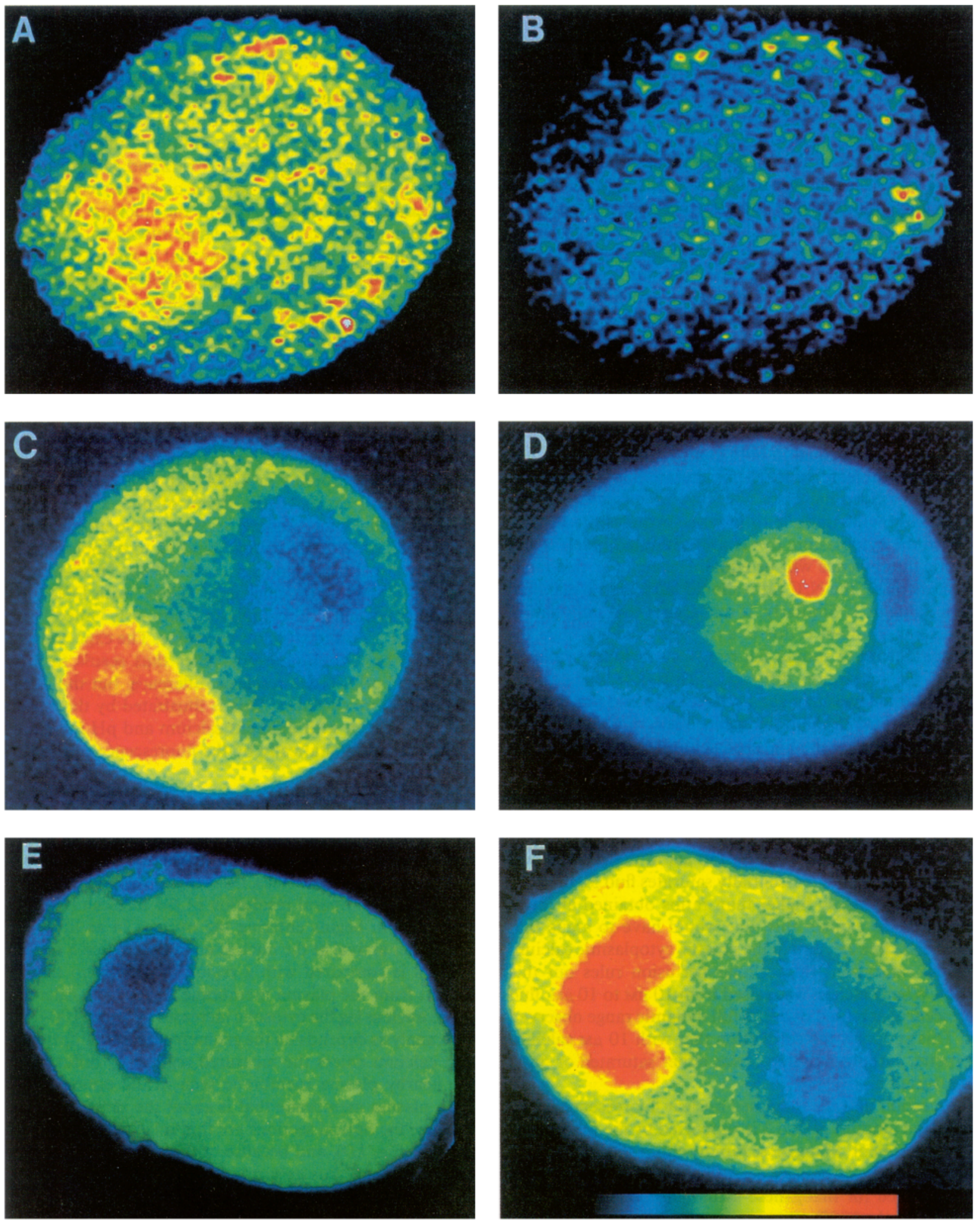

Figure 8. Nuclear signals observed with pH and other indicators. A, Cells loaded with BCECF-dextran showed a modest accumulation of indicator in the nucleus. Bath application of $20 \mathrm{~mm}$ sodium acetate caused a reversible, roughly parallel decreases in this cell's nuclear and cytosolic fluorescence, hence in $\mathrm{pH}$; the peak fluorescence decrease is shown in $\mathrm{B}$. Application of $\mathrm{NH}_{4} \mathrm{Cl}$ caused reversible fluorescence increases (not shown). Introducing large calcium loads into BCECF- or BCECF-dextran-loaded cells, via depolarization, produced only very small (less than $2 \%$ ) fluorescence decreases, suggesting quite small decreases in $\mathrm{pH}$. In cells loaded with other indicators such as calcium green dextran $(C)$ or rhod $2(D)$, both at $100 \mu \mathrm{M}$, the indicators distributed into the nucleus to an even greater extent than fluo 3 . Rhod 2 fluorescence in the nucleolus was 14.3 times cytosolic fluorescence. This is not due to a calcium gradient since calcium green, calcium green dextran, fluo 3 and indo 1 do not normally show enhanced nucleolar fluorescence. $E$, Loading of cells with fluo 3-AM preferentially labels the cytoplasmic compartment. After patch clamping, a train of depolarizations 

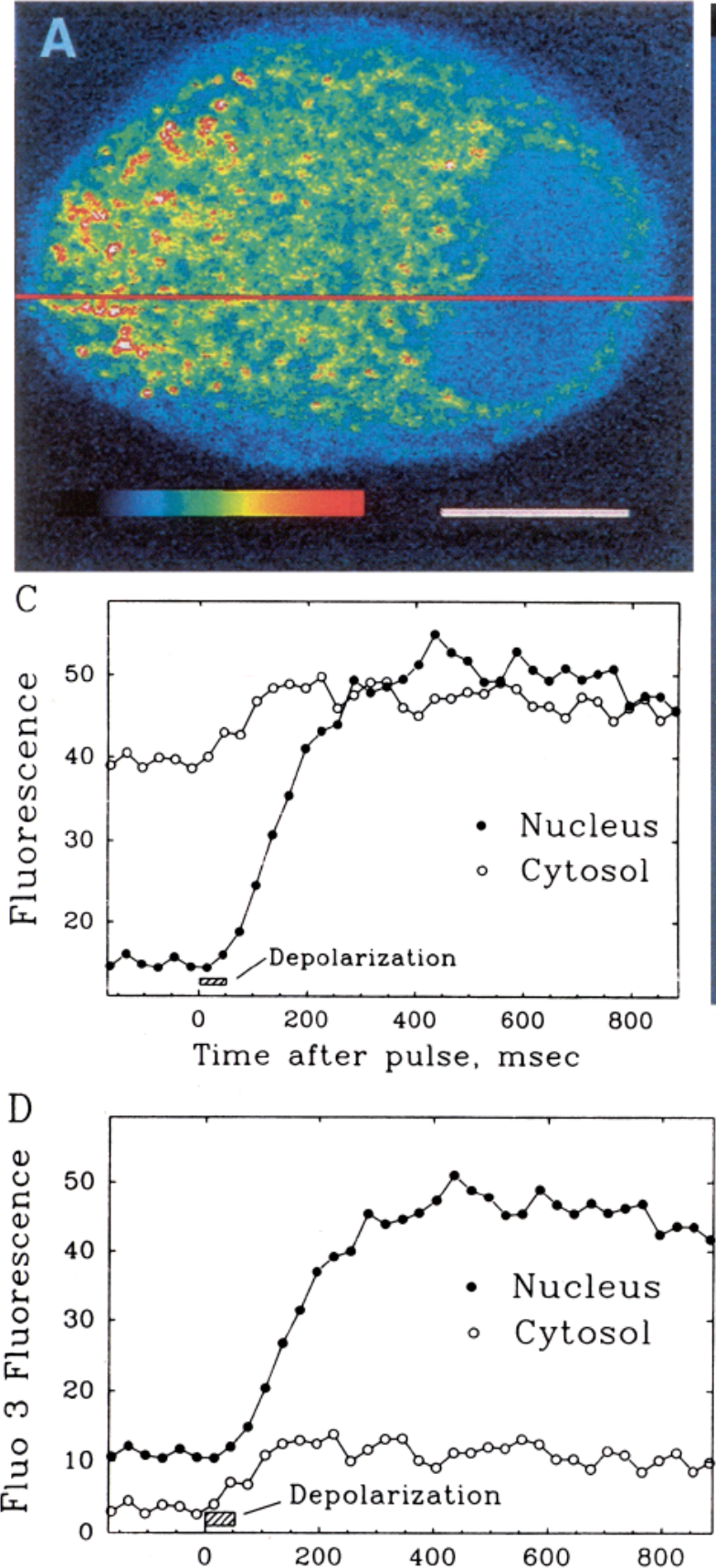

Time after pulse, msec
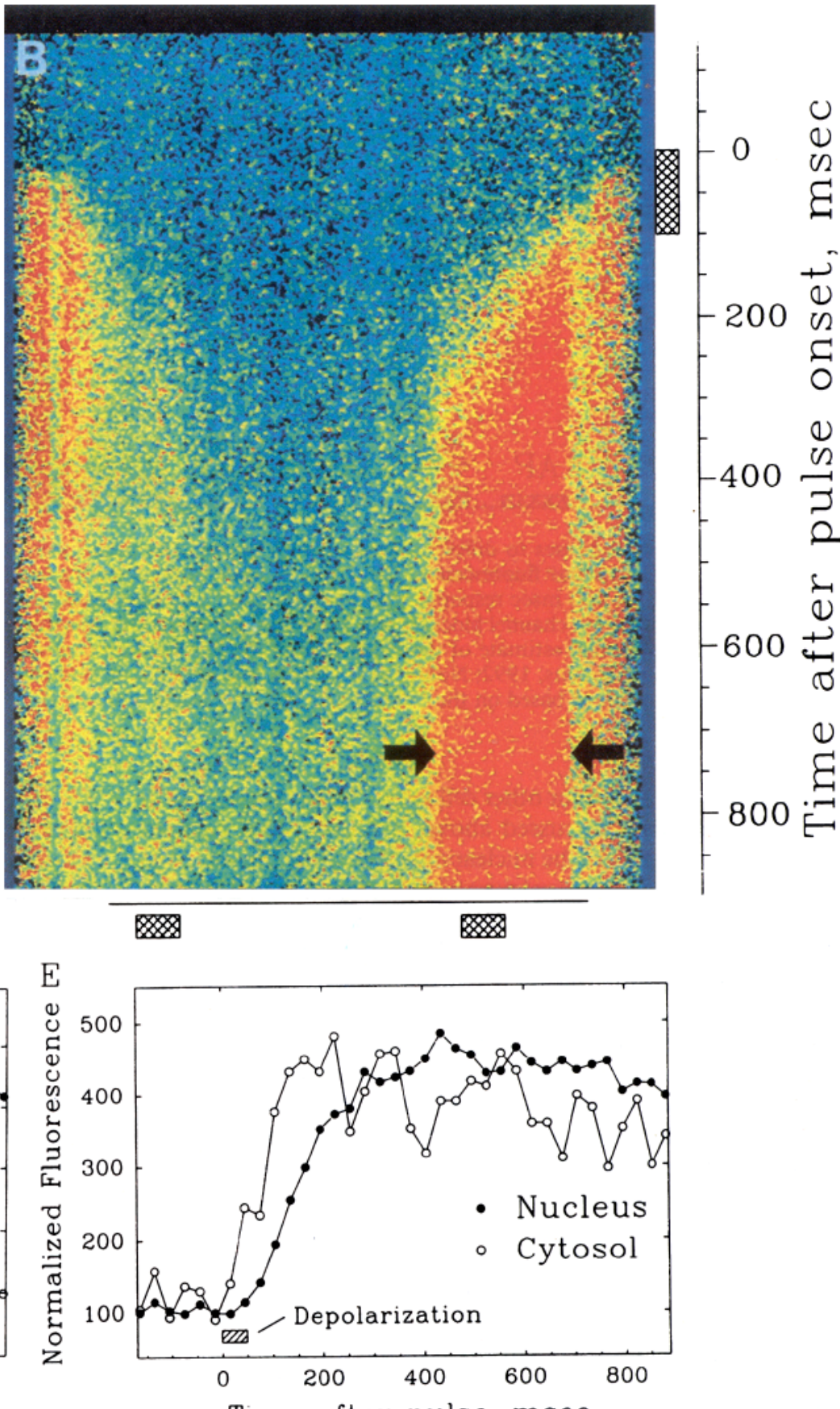

Time after pulse, msec

Figure 9. Rapid imaging of nuclear calcium influx. $A$, Cell was loaded for 7 min with $100 \mu \mathrm{M}$ fluo 3 and no BAPTA, with a relatively highresistance pipette $(4.5 \mathrm{M} \Omega)$. The cell filled relatively slowly and autofluorescent granules were still prominent causing the vertical lines in the linescan in $B$. B. The horizontal line illustrated in $A$ was scanned at $2 \mathrm{msec}$ intervals. These scans are displayed sequentially from top to bottom. Beginning $170 \mathrm{msec}$ into the scan, the cell was depolarized for $100 \mathrm{msec}$. The image shown is a ratio of this scan divided by a control linescan made just prior without stimulation. No averaging was done. Autofluorescence has not been subtracted-slight movements of the cell during patching and filling make such a correction impractical at the level of individual pixels. Calcium enters the nucleus shortly after arrival of the calcium transient. The nuclear envelope is indicated by arrows. $C$, Calcium changes in two regions equidistant from the plasma membrane (indicated below the linescan) were quantitated after depolarizing this cell for $50 \mathrm{msec}$. The measuring boxes were $3.3 \mu \mathrm{m}$ wide and $36 \mathrm{msec}$ long, which encompasses enough pixels to provide reasonably smooth data. $D$, Subtraction of autofluorescence (measured from each region before patching) shows that the nucleus contains more dye than the cytoplasm. $E$, Normalization of the signals shows that calcium rises faster in the cytoplasm than in the nucleus, but reaches about the same level. Since at this point in the experiment there was relatively little cytoplasmic dye sitting on a pedestal of autofluorescence (which is subtracted, but still noisy), the cytoplasmic trace is rather noisy.

(10 msec pulses, $3 \mathrm{~Hz}$ for $5 \mathrm{sec}$ ) caused a small nuclear response and almost no cytosolic response. Fifteen minutes after patching, the pipette was perfused with $100 \mu \mathrm{M}$ fluo 3 pentapotassium salt. Fluorescence increased sharply in both compartments requiring reduction of the photomultiplier gain; nuclear loading was prominent after $6 \mathrm{~min}(F)$. Subsequent depolarizations produced large increases in nuclear and cytosolic fluorescence. The four cells illustrated ranged from 40 to $55 \mu \mathrm{m}$ in width. 


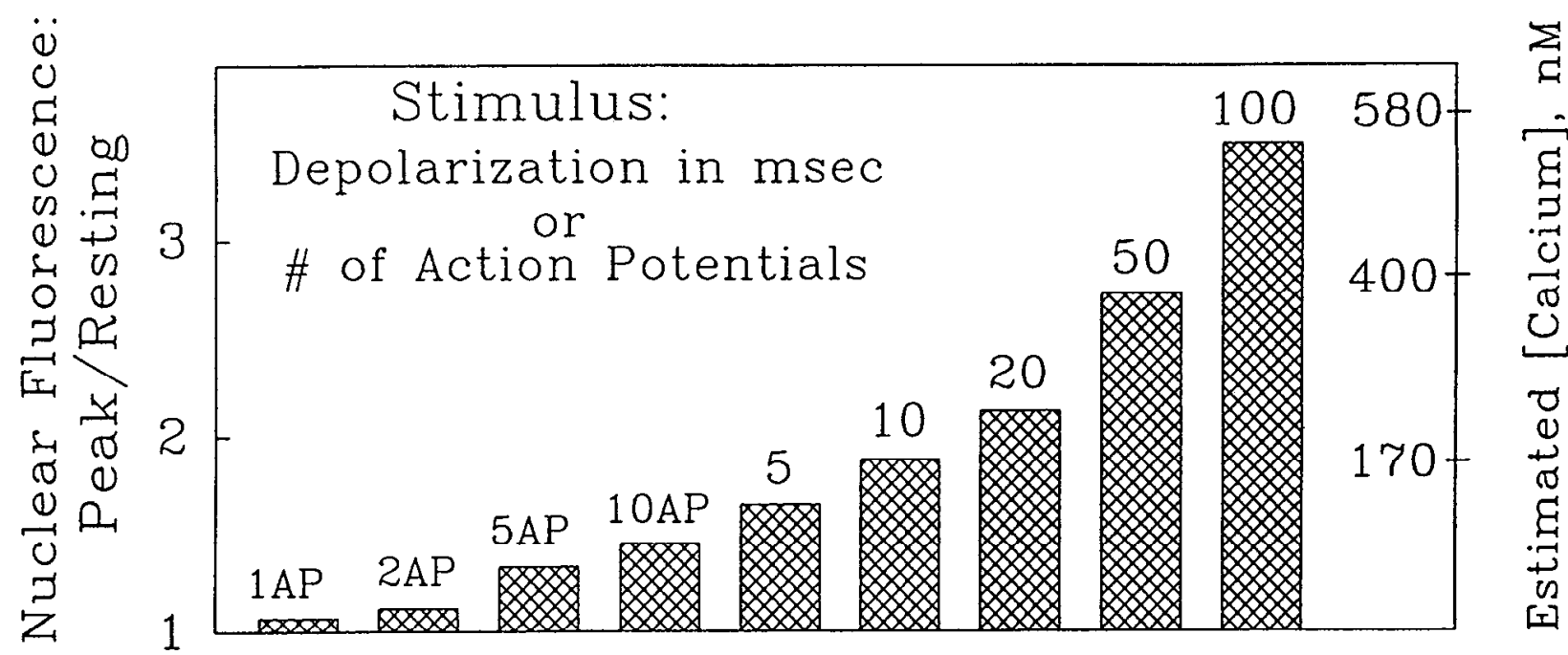

Figure 10. Nuclear responses to different-sized calcium pulses. The peak nuclear fluorescence, attained about 400 msec after a stimulation, is divided by the resting nuclear fluorescence. The 5 and 10 mscc responses arc averages of three stimuli, the 20 and 50 msec responses are averages of two stimuli, and the $100 \mathrm{msec}$ response was measured after a single stimulation. Action potentials were recorded with a standard intracellular solution without potassium channel blockers (see Materials and Methods); imaging of responses to action potentials was done in collaboration with S. D. Hocherman. A rough estimate of the magnitude of the free calcium change is given. This estimate assumes that resting calcium is 100 nm (see, e.g., Marrion and Adams, 1992; Nohmi et al., 1992), and assumes an intracellular $K_{d}$ for fluo 3 of $2 \mu \mathrm{M}$ (rough estimate from Fig. 5). The free calcium is then determined based on the intracellular dynamic range of fluo 3 (Figs. 5, 7).

ability data cited above for other cell types. Taken together with the calibration data discussed above, it appears that calcium transients diffuse across the nuclear en velope quite quickly. The observed delay in nuclear calcium signals is quite small relative to the time scale of nuclear activities such as gene expression.

An alternative explanation is that the nuclear envelope and nuclear pores are impermeant to calcium as suggested by studies on smooth muscle (Williams et al., 1985, 1987; Neylon et al., 1990). If so, one might propose that calcium rapidly appears in the nucleus as a result of an active mechanism in the nuclear envelope. Calcium signals detected at the nuclear envelope would be relayed to the inner nuclear membrane and then calcium would be released into the nucleus from this perinuclear space. If this is correct, then when different-sized calcium pulses were produced by depolarization (Fig. 10), the nuclear envelope would have had to measure the size of the cytosolic calcium signal and, within milliseconds, begin releasing a proportionately sized amount of calcium into the nucleus. Although $\mathrm{IP}_{3}$ and ryanodine receptors and ATP-dependent calcium pumps permit the nuclear envelope to function as calcium-storage organelle (see introductory remarks), these mechanisms are not known to be capable of introducing a broad, but finely graded range of calcium loads into the nucleus.

Alternatively, a nuclear membrane potential might explain both the increased resting nuclear fluorescence and the graded size of the nuclear responses to various calcium loads. Early reports of a potassium-generated nuclear membrane potential of -5 to $-15 \mathrm{mV}$ (Loewenstein and Kanno, 1963) have been supported by more recent studies (Mazzanti et al., 1990). A - 10 $\mathrm{mV}$ membrane potential would induce a 2.16 -fold resting N/C calcium gradient based on the Nernst equation. However, there are several difficulties. First, if the N/C fluorescence gradient was due to a voltage-induced calcium gradient, then the fluorescence gradient should have been abolished when cytoplasmic fluo 3 was saturatcd with calcium or manganese. Second, because fluo 3 has a charge of -5 , it should be strongly repelled by the $-10 \mathrm{mV}$ nuclear potential. In fact, a 6.85 -fold gradient of cytosolic/nuclear fluo 3 is predicted by the Nernst equation. Finally, other workers report that the nucleus and cytoplasm are isopotential (Palmer and Civan, 1977; Paine et al., 1981) and that N/C potassium gradients do not exist (Century and Horowitz, 1974; Paine et al., 1981). In summary, the simplest and most complete explanation for the calibration and rapid imaging data is that calcium passively equilibrates between the nucleus and cytoplasm.

\section{Biophysics, gradients, and nuclear amplification}

Organelles. The charged form of fluo 3 appears to enter membrane-bound, cytosolic organelles gradually. A gradual decline in N/C ratio is observed at all calcium concentrations (Fig. 6), consistent with entry of fluo 3 into compartments such as Golgi, mitochondria, and endoplasmic reticulum. Also, the modest increase in $\mathrm{N} / \mathrm{C}$ fluorescence ratio that occurs upon switching from low calcium to high calcium or high manganese (Fig. 7) suggests that part of the cytoplasmic fluo 3 signal is not responding to changes in the cytoplasmic concentration of divalent cations. Fluo 3 inside organelles may be saturated with calcium (Chandra et al., 1991; Krause, 1991; Terasaki and Sardet, 1991; Glennon et al., 1992) and would therefore constitute a substantial fluorescence signal that is insensitive to changes in cytosolic calcium.

This problem also applies to ratiometric dyes because the signal originating from high-calcium containing organelles would contribute unequally to the two wavelengths being used to measure cytoplasmic calcium, shifting the cytoplasmic ratio away from the nuclear ratio. Furthermore, the internal environment of organelles, for example, low pH or altered protein composition, may cause additional spectral shifts, such as the "blue shifts" observed for fura 2 and indo 1 (Konishi et al., 1988; Hove-Madsen and Bers, 1992). This further complicates the interpretation of ratiometric data.

Compartmentalization is a particularly serious problem when 
cells are loaded with the membrane-permeant form of the calcium indicators - the acetoxymethyl esters or AM dyes. These AM dyes will enter organelles to a much greater extent than the charged form of the dyes producing a pool of indicator that is unresponsive to extraorganellar calcium changes (Fig. $8 E$; indo 1 and fura 2: Blatter and Wier, 1990; Terasaki and Sardet, 1991; Glennon et al., 1992; Segal and Manor, 1992). Spectral shifts in ratiometric dyes can be even more pronounced when using the AM form (Borzak et al., 1992; Hove-Madsen and Bers, 1992). These problems make comparison of nuclear/cytosolic fluorescence ratios even more tenuous. The apparent amplification of calcium transicnts, by the nucleus of neurons loaded with AM dyes, might therefore be accounted for by different degrees of indicator compartmentalization (Przywara et al., 1991; Birch et al., 1992; Segal and Manor, 1992).

Differences in the aqueous space of the nucleus and cytosol. A separate issue is that the aqueous phase of the nucleus and cytoplasm are distinct environments. The behavior of calcium indicators is profoundly altered by binding to proteins-their dissociation constants generally increase by three- to fivefold (fura 2, Konishi et al., 1988; indo 1, Hove-Madsen and Bers, 1992; fluo 3, Harkins et al., 1993; fura red, Kurebayashi et al., 1993). Viscosity differences (Lang et al., 1986; Poenie, 1990) and perhaps intercalation of indicators into DNA (Neidle and Abraham, 1984) might also alter their responses. Any environmental differences between the nucleus and cytosol might therefore shift the indicator's $K_{d}$, quantum efficiency, or spectral behavior. This necessitates independent calibration of nuclear and cytosolic signals for ratiometric and single wavelength indicators alike. The main conclusions presented here are unlikely to be altered by such problems. Each compartment was calibrated separately, and even if the $K_{d}$ of fluo 3 was shifted by a factor of 5 , in for example, only the cytoplasm, fluo 3 would still have been saturated in both compartments, particularly in the manganese expcriments. Indecd, the relative constancy of the N/C ratio over calcium levels spanning fluo 3's dynamic range suggests that the $K_{d}$ of fluo 3, while it may be much increased inside cells, is similar in the nucleus and cytoplasm.

Amplification observed under whole-cell patch clamp. Hernandez-Cruz et al. (1990) loaded sympathetic neurons via patch pipettes, thereby minimizing the problem of dye compartmentalization. While they realized that a significant amount of the exaggerated nuclear fluorescence increase was due to accumulation of fluo 3 in the nucleus of the cell, they attributed the balance of the N/C difference to an amplified nuclear response. Two considerations affect this interpretation. First, the optical situation in use at that time (imaging through a plastic petri dish with a lower NA objective; Fig. $3 D$ ) did not permit adequate measurement of nuclear and cytoplasmic autofluorescence, as revealed by their somewhat smaller resting $\mathrm{N} / \mathrm{C}$ fluorescence ratios. I measured the optical section thickness of this arrangement to be between 6 and $9 \mu \mathrm{m}$, which means that "nuclear" signals, for example, autofluorescence, could easily be contaminated by overlying cytosolic signals. The resulting artifactual elevation of the nuclear baseline would result in an underestimation of resting nuclear fluo 3 and an apparent amplification. Internalization of fluo 3 into organelles and a decreased optical sensitivity could also contribute to this apparent amplification. Indeed, the internal perfusion with $10 \mu \mathrm{M}$ calcium produced a larger increase in nuclear than cytosolic fluorescence (Fig. 7 $\mathrm{A}$ ) and could be viewed as a "nuclear amplification," if taken out of context.
Calibration. Fluo 3 is most useful for making two types of calcium measurements. First, it is useful for measuring small, fast changes in calcium, where the concentration of fluo 3 is not changing. Second, it is useful in measuring the relative fluorescence change in regions of the cell that can be resolved by confocal microscopy and independently calibrated. The biggest drawback to single wavelength indicators such as fluo 3 is that determining absolute levels of calcium is not easy. This is because an increase in fluorescence can be due to either an increase in calcium or an increase in concentration of fluo 3. This problem does not affect the present results - the measurements made wcre of the two types just mentioned. However, efforts to make rough estimates of absolute calcium levels are worthwhile.

One approach to calibration is to pick a time point where sufficient fluo 3 has entered the cell to provide adequate signal, yet entry of fluo 3 into organelles is still minor. Different time points in Figure 5, $C$ and $D$, might be chosen for this purpose, and these signals are roughly correlated with the free calcium level in the pipette, taking into account the apparent shift in $K_{d}$. However, there is obvious variability in the filling rate and fluorescence of different cells. Furthermore, the use of $10 \mathrm{~mm}$ BAPTA in the pipette to control cellular calcium has definite limitations. With free calcium in the pipette fixed at low levels, for example, $10 \mathrm{nM}$, the cell may compensate by opening calcium channels or by releasing calcium from internal stores. Similarly, when attempting to raise calcium to micromolar levels, cellular calcium pumps and exchangers are likely to compensate by extruding calcium from the cell, possibly depleting calcium from the tip of the pipette.

Nonetheless, it appears that most of the desired control of free calcium was achieved: the response to perfusion from 10 nM to $10 \mu \mathrm{M}$ calcium showed nearly all of the fluorescence increase expected from the droplet calibration. Because the dynamic range of the dye in situ appears similar to its behavior in droplets of intracellular solution, an alternative calibration scheme might be employed. If resting free calcium levels are fairly consistent, then fluorescence increases can be assumed to represent an increase above that level, and the dynamic range and estimated $K_{d}$ measurements obtained in Figures 5 and 7 can be applied. Fura 2 measurements made on these cells in culture (Marrion et al., 1991; Marrion and Adams, 1992) and in intact sympathetic ganglia (Nohmi et al., 1992) suggest that resting calcium is about $80-100 \mathrm{nM}$. In Figure 10, resting calcium was assumed to be $100 \mathrm{nM}$ and this method was employed. One caveat is that those fura 2 measurements used a $K_{d}$ that was not corrected for protein binding and, in the Nohmi et al. study, used AM loading, both of which render uncertain the true resting calcium levels. In muscle cells, where the issue of resting free calcium has been addressed quite vigorously, the most comprehensive work has concluded only that calcium rests between 100 and 300 nM (Harkins et al., 1992; Kurebayashi et al., 1993).

A complementary calibration approach is made possible by the ability to flood neurons rapidly with calcium by opening calcium channels. Because the dynamic range of fluo 3 in cultured sympathetic neurons has been established, the increase in fluorescence after calcium influx gives an upper limit to where free calcium rested before stimulation. For example, the $50 \mathrm{msec}$ depolarization shown in Figure 2 induced a large increase in fluorescence (5.8-fold) under the plasma membrane. From the calibration curve in Figure $5 \mathrm{~A}$, corrected for $K_{d}$, a 5.8-fold increase requires the prestimulation level of calcium to have been 
no more than about $400 \mathrm{~nm}$. A higher resting level of calcium would have precluded this degree of fluorescence increase. Had a resting calcium level of $400 \mathrm{~nm}$ been used in calculating the size of the nuclear responses in Figure 10, those responses would have been larger in absolute size and would have reached much higher levels.

Advantages of fluo 3 and intracellular perfusion. In spite of problems with calibration, fluo 3 has several advantages relative to shorter wavelength dyes such as fura 2 and indo 1 . It is compatible with BAPTA, a fast calcium chelator that does not give off protons on binding calcium, unlike the more traditional chelator EGTA. BAPTA's ultraviolet fluorescence limits its use with fura 2 and indo 1 . A second advantage of fluo 3 is its large fluorescence increase upon binding calcium; this allows measurement of small signals and the use of minimal amounts of exciting light, thereby minimizing photobleaching and photodynamic damage (see e.g., van den Pol et al., 1992). A useful feature of fluo 3's labeling was that the nucleus was clearly delimited, allowing ready acquisition of nuclear and cytosolic calibration curves. Because fluo 3 is a nonratiometric indicator, it will be less affected by small spectral shifts that can be magnified when making ratiometric measurements. The calibration approach presented is also applicable to other single wavelength indicators such as calcium green dextran, which has been extremely useful in studying neuronal population dynamics (O'Malley et al., 1992; O'Donovan et al., 1993; Fetcho and O'Malley, unpublished observations).

A second advantage of this approach is that calibration via intraccllular perfusion may be less disruptive than calibration using ionophores. The membrane-dissolving nature of ionophores and their solvents raises the possibility that the distribution of dye and ions may be affected during the calibration protocol. It is not clear that ionophores can be used to generate "full-dynamic-range" calibration curves with subcellular resolution. In contrast, with intracellular perfusion, only the concentration of free calcium is changed and measurements can be made over a broad range of calcium concentrations. One drawback is that patch clamping dialyses the cell and may cause the loss of significant cytoplasmic constituents. A final point is that in patch-clamped neurons, it may be possible to saturate fluo 3 rapidly with calcium, thus generating a quick calibration. These approaches should complement the use of ratiometric dyes and ionophoric calibrations.

Persistent calcium gradients. Calcium gradients have often been reported in circumstances where there are no apparent diffusion barriers. The nucleolus, highlighted in Figures $1 C$ and $8 D$, is of interest in this regard. These "apparent calcium gradients" are not due to a dynamic calcium response, although similar observations have been so interpreted (Birch et al., 1992). In the present experiments with fluo 3 , the nucleolus initially tends to be dimmer than the nucleus, and after a prolonged period of recording, usually with intermittent stimulation, the nucleolus can increase in fluorescence, suggesting a change in state of the nucleolus or gradual binding of fluo 3 . Persistent calcium gradients have also been reported in nerve cell processes (Connor et al., 1988; Muller and Connor, 1991; Wadman and Connor, 1992), where no barriers to the diffusion of calcium are evident. While these gradients are thought to result from a sustained influx of calcium, full-dynamic-range calibration of regions showing such gradients would more strongly support this contention. Such approaches can rule out possible imaging artifacts such as the long-lasting fluorescence changes that are produced by intense illumination (Regehr and Tank, 1992) and often highly localized (O'Malley and Burbach, unpublished observations).

\section{Neurobiological significance}

Calcium is likely to activate calcium binding proteins, proteases, and nucleases inside the nucleus (e.g., Bachs et al., 1992; Joseph et al., 1993; Lerea and McNamara, 1993; Matter et al., 1993; Mellgren et al., 1993) and is thought to play a role in ischemia, epilepsy, and Alzheimer's disease (Choi, 1992; Duman et al., 1992; Heizmann and Braun, 1992; Mattson et al., 1992, 1993). The size and time course of nuclear calcium signals may therefore influence the progression of these neurodegenerative processes. Imaging techniques showing persistent $\mathrm{N} / \mathrm{C}$ gradients might not provide realistic measurements of the size and time course of nuclear calcium dynamics.

Genc cxpression is also strongly influcnced by calcium (Rodland et al., 1990, 1992; Sheng et al., 1990; Murphy et al., 1991). Calcium can induce the phosphorylation of a transcription factor (CREB) within $30 \mathrm{sec}$ after depolarization (D. D. Ginty and M. E. Greenberg, personal communication), suggesting that calcium may act quickly within the nucleus. An alternative model is that calcium activates proteins at a remote site, such as a dendritic spine, and the activated proteins then migrate to the nucleus. For the CREB result, however, the speed of phosphorylation means that either calcium or a small, diffusible third messenger is acting directly in the nucleus. Even if a third messenger is involved, the calcium permeability of the envelope is relevant: an impermeable nuclear envelope should exclude calcium ions and third messengers alike.

Because different-sized nuclear calcium loads are a possible explanation for the differential regulation of hippocampal gene expression (Bading et al., 1993), confocal microscopy may be a useful tool in exploring the regulation of such nuclear functions. Indeed, a recent study reports that a difference in tetanizing stimulation paradigms of 10 pulse trains ( 80 pulses total) versus 50 pulse trains has dramatically different effects in the synaptic activation of transcription factors (Worley et al, 1993). It remains to be determined what the threshold is for calcium's genetic actions, and whether the nuclear calcium loads observed after a few action potentials are significant.

\section{References}

Avila RS, Sobierajski LM, Kaufman AE (1992) Towards a comprchensive volume visualization system. Proceedings, Visualization 1992, Boston, MA, pp 13-20.

Bachs O, Agell N, Carafoli E (1992) Calcium and calmodulin function in the cell nucleus. Biochim Biophys Acta 1113:259-270.

Bading H, Ginty DD, Greenberg ME (1993) Regulation of gene expression in hippocampus by distinct calcium signaling pathways. Science 260:181-186.

Bartlett JD, Luethy JD, Carlson SG, Sollott SJ, Holbrook NJ (1992) Calcium ionophore A23187 induces expression of the growth arrest and DNA damage inducible CCAAT/enhancer-binding protein-related gene, GADD 153. J Biol Chem 267:20465-20470.

Birch BD, Eng DL, Kocsis JD (1992) Intranuclear calcium transients during neurite regeneration of an adult mammalian neuron. Proc Natl Acad Sci USA 89:7978-7982.

Blatter LA, Wier WG (1990) Intracellular diffusion, binding and compartmentalization of the fluorescent calcium indicators indo-1 and fura-2. Biophys J 58:1491-1499.

Borzak S, Reers M, Arruda J, Sharma VK, Sheu SS, Smith TW, Marsh JD (1992) Sodium efflux mechanisms in ventricular myocytes: measurement of intracellular sodium with sodium-binding benzofuran isophthalate. Am J Physiol 263:H866-H874. 
Century TJ, Horowitz SB (1974) Sodium exchange in the cytoplasm and nucleus of amphibian oocytes. J Cell Sci 16:465-471.

Chandra S, Kable EP, Morrison GH, Webb WW (1991) Calcium sequestration in the Golgi apparatus of cultured mammalian cells revealed by laser scanning confocal microscopy and ion microscopy. J Cell Sci 100:747-752.

Choi DW (1987) Ionic dependence of glutamate neurotoxicity. J Neurusci 7:369-379.

Choi DW (1992) Excitotoxic cell death. J Neurobiol 9:1261-1276.

Christ GJ, Moreno AP, Melman A, Spray DC (1992) Gap junctionmediated intercellular diffusion of calcium in cultured human corporal smooth muscle cells. Am J Physiol 263:C373-C383.

Connor JA, Wadman WJ, Hockberger PE, Wong RKS (1988) Sustained dendritic gradients of calcium induced by excitatory amino acids in CA1 hippocampal neurons. Science 240:649-653.

Dani JW, Chernjavsky A, Smith SJ (1992) Neuronal activity triggers calcium waves in hippocampal astrocyte networks. Neuron 8:429440.

Dingwall C, Laskey RA (1986) Protein import into the cell nucleus. Annu Rev Cell Biol 2:367-390.

Dowd DR, MacDonald PN, Komm BS, Haussler MR, Miesfeld RL (1992) Stable expression of the calbindin-d28K complementary DNA interferes with the apoptotic pathway in lymphocytes. Mol Endocrinol 6:1843-1848.

Duman RS, Craig JS, Winston SM, Deutch AY, Hernandez TD (1992) Amygdala kindling potentiates seizure-stimulated immediate-early gene expression in rat cerebral cortex. J Neurochem 59:1753-1760.

Fabiato A, Fabiato F (1979) Calculator programs for computing the composition of the solutions containing multiple metals and ligands used for experiments in skinned muscle cells. J Physiol (Paris) 75: 463-505.

Finlay DR, Forbes DJ (1990) Reconstitution of biochemically altered nuclear pores: transport can be eliminated and restored. Cell 60:1729.

Finlay DR, Newmeyer DD, Price TM, Forbes DJ (1987) Inhibition of in vitro nuclear transport by a lectin that binds to nuclear pores. $\mathrm{J}$ Cell Biol 104:189-200.

Ginty DD, Bading H, Greenberg ME (1992) Trans-synaptic regulation of gene expression. Curr Opin Neurobiol 2:312-316.

Glennon MC, Bird GSJ, Takemura H, Thastrup O, Leslie BA, Putney JW (1992) In situ imaging of agonist-sensitive calcium pools in AR4-2J pancreatoma cells. J Biol Chem 267:25568-25575.

Greenberg ME, Ziff EB, Greene LA (1986) Stimulation of neuronal acetylcholine receptors induces rapid gene transcription. Science 234: 80-83.

Harkins AB, Kurebayashi N, Baylor SM (1993) Resting myoplasmic free calcium in frog skeletal muscle fibers estimated with fluo 3 . Biophys J 65:865-881.

Harrison SM, Bers DM (1987) The effect of temperature and ionic strength on the apparent Ca-affinity of EGTA and the analogous $\mathrm{Ca}$ chelators BAPTA and dibromo-BAPTA. Biochim Biophys Acta 925: 133-143.

Haugland RP (1992) Handbook of fluorescent probes and research chemicals. Eugene, OR: Molecular Probes.

Heizmann CW, Braun K (1992) Changes in calcium-binding proteins in human neurodegenerative disorders. Trends Neurosci 15:259-264.

Herman B, Roe MW, Wray HB, Clemmons D (1987) Platelet-derived growth factor-induced alterations in vinculin distribution in porcine vascular smooth muscle cells. Cell Motil Cytoskel 8:91-105.

Hernandez-Cruz A, Sala F, Adams PR (1990) Subcellular calcium transients visualized by confocal microscopy in a voltage-clamped vertebrate neuron. Science 247:858-862.

Hernandez-Cruz A, Sala F, Connor JA (1991) Stimulus-induced nuclcar calcium signals in fura-2 loaded amphibian neurons. Ann NY Acad Sci 635:416-420.

Himpens B, De Smedt H, Droogmans G, Casteels R (1992a) Differences in regulation between nuclear and cytoplasmic calcium in cultured smooth muscle cells. Am J Physiol 263:C95-C105.

Himpens B, De Smedt H, Casteels R (1992b) Kinetics of nucleocytoplasmic calcium transients in DDTI MF-2 smooth muscle cells. Am J Physiol 263:C978-C985.

Hinshaw JE, Carragher BO, Milligan RA (1992) Architecture and design of the nuclear pore complex. Cell 69:1133-1141.

Holliday J, Adams RJ, Sejnowski TJ, Spitzer NC (1991) Calciuminduced release of calcium regulates differentiation of cultured spinal neurons. Neuron 7:787-796.
Horowitz SB (1972) The permeability of the amphibian oocyte nucleus, in situ. J Cell Biol 54:609-625.

Horowitz SB, Moore LC (1974) The nuclear permeability, intracellular distribution and diffusion of inulin in the amphibian oocyte. J Cell Biol 60:405-415.

Hove-Madsen L, Bers DM (1992) Indo-1 binding to protein in permeabilized ventricular myocytes alters its spectral and calcium binding properties. Biophys J 63:89-97.

Joseph R, Li W, Han E (1993) Neuronal death, cytoplasmic calcium and internucleosomal DNA fragmentation: evidence for DNA fragments being released from cells. Mol Brain Res 17:70-76.

Kao JPY, Harootunian AT, Tsien RY (1989) Photochemically generated cytosolic calcium pulses and their detection by fluo-3. J Biol Chem 264:8179-8184.

Konishi M, Olson A, Hollingworth S, Baylor SM (1988) Myoplasmic binding of fura- 2 investigated by steady state fluorescence and absorbance measurements. Biophys J 54:1089-1104.

Krause KH (1991) Calcium-storage organelles. FEBS Lett 285:225229.

Kuffler SW, Sejnowski TJ (1983) Peptidergic and muscarinic excitation at amphibian sympathetic synapses. J Physiol (Lond) 341:257278.

Kurebayashi N, Harkins AB, Baylor SM (1993) Use of fura red as an intracellular calcium indicator in frog skeletal muscle fibers. Biophys J 64:1934-1960.

Lang I, Scholz M, Peters R (1986) Molecular mobility and nucleocytoplasmic flux in hepatoma cells. J Cell Biol 102:1183-1190.

Lanini L, Bachs O, Carafoli E (1992) The calcium pump of the liver nuclear membrane is identical to that of endoplasmic reticulum. J Biol Chem 267:11548-1 1552.

Lerea LS, McNamara JO (1993) Ionotropic glutamate receptor subtypes activate $c$-fos transcription by distinct calcium-requiring intracellular signaling pathways. Neuron 10:31-41.

Loewenstein WR, Kanno Y (1963) Some electrical properties of a nuclear membrane examined with a microelectrode. J Gen Physiol 46:1123-1140.

Lopez HS (1992) Kinetics of G protein-mediated modulation of the potassium M-current in bullfrog sympathetic neurons. Neuron 8:725736.

Malviya AN, Rogue P, Vincendon G (1990) Stereospecific inositol $1,4,5-{ }^{32} \mathrm{P}$-trisphosphate binding to isolated rat liver nuclei: evidence for inositol trisphosphate receptor-mediated calcium release from the nucleus. Proc Natl Acad Sci USA 87:9270-9274.

Marrion NV, Adams PR (1992) Release of intracellular calcium and modulation of membrane currents by caffeine in bull-frog sympathetic neurones. J Physiol (Lond) 445:515-535.

Marrion NV, Zucker RS, Marsh SJ, Adams PR (1991) Modulation of M-current by intracellular calcium. Neuron 6:533-545.

Matter N, Ritz MF, Freyermuth S, Rogue P, Malviya A (1993) Stimulation of nuclear PKC leads to phosphorylation of nuclear IP3-receptor and accelerated calcium release by IP3 from isolated rat liver nuclei. J Biol Chem 268:732-736.

Mattson MP, Cheng B, Davis D, Bryant K, Lieberburg I, Rydel RE (1992) $\beta$-Amyloid peptides destabilize calcium homeostasis and render human cortical neurons vulnerable to excitotoxicity. J Neurosci 12:376-389.

Mattson MP, Cheng B, Culwell AR, Esch FS, Lieberburg I, Rydel RE (1993) Evidence for excitoprotective and intraneuronal calcium-regulating roles for secreted forms of the $\beta$-amyloid precursor protein. Neuron 10:243-254.

Mazzanti M, DeFelice LJ, Cohen J, Malter H (1990) Ion channels in the nuclear envelope. Nature 343:764-767.

Mazzoni M, Bertagnolo V, Neri LM, Carini C, Marchisio M, Milani D, Manzoli FA, Capitani S (1992) Discrete subcellular localization of phosphoinositidase $\mathrm{C}$ subtypes in $\mathrm{PCl} 2$ rat pheochromocytoma cells. Biochem Biophys Res Commun 187:114-120.

McConkey DJ, Hartzell P, Nicotera P, Orrenius S (1989) Calciumactivated DNA fragmentation kills immature thymocytes. FASEB J 3:1843-1849.

Mellgren RL, Song K, Mericle MT (1993) $m$-Calpain requires DNA for activity on nuclear proteins at low calcium concentrations. J Biol Chem 268:653-657.

Minta A, Kao JPY, Tsien RY (1989) Fluorescent indicators for cytosolic calcium based on rhodamine and fluorescein chromophores. J Biol Chem 264:8171-8178.

Moore MS, Blobel G (1992) The two steps of nuclear import, targeting 
to the nuclear envelope and translocation through the nuclear pore, require different cytosolic factors. Ccll 69:939-950.

Muller W, Connor JA (1991) Dendritic spines as individual neuronal compartments for synaptic calcium responses. Nature 354:73-76.

Murphy TH, Worley PF, Baraban JM (1991) L-type voltage-sensitive calcium channels mediate synaptic activation of immediate early genes. Neuron 7:625-635.

Neher E, Augustine GJ (1992) Calcium gradients and buffers in bovine chromaffine cells. J Physiol (Lond) 450:273-301.

Neidle S, Abraham Z (1984) Structural and sequence-dependent aspects of drug intercalation into nucleic acids. CRC Crit Rev Biochem 17:73-121.

Neylon CB, Hoyland J, Mason WT, Irvine RF (1990) Spatial dynamics of intracellular calcium in agonist-stimulated vascular smooth muscle cells. Am J Physiol 259:C675-C686.

Nicotera P, McConkey DJ, Jones DP, Orrenius S (1989) ATP stimulates calcium uptake and increases the free calcium concentration in isolated rat liver nuclei. Proc Natl Acad Sci USA 86:453-457.

Nicotera P, Orrenius S, Nilsson T, Berggren PO (1990) An inositol 1,4,5,-trisphosphate-sensitive calcium pool in liver nuclei. Proc Natl Acad Sci USA 87:6858-6862.

Nitsch R, Frotscher M (1992) Reduction of posttraumatic transneuronal "early gene" activation and dendritic atrophy by the $N$-methylD-aspartate receptor antagonist MK-801. Proc Natl Acad Sci USA 89:5197-5200.

Nohmi M, Hua SY, Kuba K (1992) Intracellular calcium dynamics in response to action potentials in bullfrog sympathetic ganglion cells. J Physiol (Lond) 458:171-190.

O'Donovan MJ, Ho S, Sholomenko G, Yee W (1993) Real-time imaging of ncurons retrogradcly and antcrogradcly labclicd with calciumsensitive dyes. J Neurosci Methods 46:91-106.

O'Malley DM, Lu SM, Guido W, Adams PR (1992) Transport of calcium green dextran visualized via confocal microscopy in the visual system of the rat. Soc Neurosci Abstr 18:142.

O'Malley DM, Yu SP, Burbach BJ, Adams PR (1993) Evidence against persistent nuclear/cytoplasmic calcium gradients in bullfrog sympathetic neurons. Soc Neurosci Abstr 19:1113.

Paine PL, Moore LC, Horowitz SB (1975) Nuclear envelope permeability. Nature 254:109-114.

Paine PL, Pearson TW, Tluczek LJM, Horowitz SB (1981) Nuclear sodium and potassium. Nature 291:258-261.

Palmer LG, Civan MM (1977) Distribution of sodium, potassium and chloride between nucleus and cytoplasm in Chironomus salivary gland cells. J Membr Biol 33:41-61.

Peters R (1984) Nucleocytoplasmic flux and intracellular mobility in single hepatocytes measured by fluorescence microphotolysis. EMBO J 3:1831-1836.

Peters R (1986) Fluorescence microphotolysis to measure nucleocytoplasmic transport and intracellular mobility. Biochim Biophys Acta 864:305-359.

Poenie M (1990) Alteration of intracellular fura-2 fluorescence by viscosity: a simple correction. Cell Calcium 11:85-92.

Pribnow D, Muldoon LL, Fajardo M, Theodor L, Chen LYS, Magun BE (1992) Endothelin induces transcription of fos/jun family genes: a prominent role for calcium ions. Mol Endocrinol 6:1003-1012.

Przywara DA, Bhave SV, Bhave A, Wakade TD, Wakade AR (1991) Stimulated rise in neuronal calcium is faster and greater in the nucleus than the cytosol. FASEB J 5:217-222.

Pusch M, Neher E (1988) Rates of diffusional exchange between small cells and a measuring patch pipette. Pfluegers Arch 411:204-211.
Regehr WG, Tank DW (1992) Calcium concentration dynamics produced by synaptic activation of CA1 hippocampal pyramidal cells. $\mathrm{J}$ Neurosci 12:4202-4223.

Rodland KD, Muldoon LL, Lenormand P, Magun BE (1990) Modulation of RNA expression by intracellular calcium. J Biol Chem 265: 11000-11007.

Rodland KD, Lenormand P, Muldoon LL, Magun BE (1992) Regulation of transin/stromelysin and VL30 gene expression by intracellular calcium. J Invest Dermatol 98:12S-16S

Ross CA, Meldolesi J, Milner TA, Satoh T, Supattapone S, Snyder SH (1989) IP3 receptor localized to endoplasmic reticulum in cerebellar Purkinje neurons. Nature 339:468-470.

Sala F, Hernandez-Cruz A (1990) Calcium diffusion modeling in a spherical neuron: relevance of buffering properties. Biophys J 57:313324.

Segal M, Manor D (1992) Confocal microscopic imaging of calcium in cultured rat hippocampal neurons following exposure to NMDA. J Physiol (Lond) 448:655-676.

Sheng M, Mcfadden G, Greenberg ME (1990) Membrane depolarization and calcium induce c-fos transcription via phosphorylation of transcription factor CREB. Neuron 4:571-582.

Szekely AM, Costa E, Grayson DR (1990) Transcriptional program coordination by $N$-methyl-D-aspartate sensitive glutamate receptor stimulation in primary cultures of cerebellar neurons. Mol Pharmacol 38:624-633.

Terasaki M, Sardet C (1991) Demonstration of calcium uptake and release by sea urchin egg cortical endoplasmic reticulum. J Cell Biol 115:1031-1037.

Tsien RY (1980) New calcium indicators and buffers with high selectivity against magnesium and protons: design, synthesis, and properties of prototype structures. Biochemistry 19:2396-2404.

Uneyama C, Uneyama H, Takahashi M, Akaike N (1993) Cytoplasmic pH regulates ATP-induced calcium-dependent potassium-current oscillation in rat megakaryocytes. Biochem J 295:317-320.

van den Pol AN, Finkbeiner SM, Cornell-Bell AH (1992) Calcium excitability and oscillations in suprachiasmatic nucleus neurons and glia in vitro. J Neurosci 12:2648-2664.

Wadman WJ, Connor JA (1992) Persisting modification of dendritic calcium influx by excitatory amino acid stimulation in isolated CAl neurons. Neurosci 48:293-305.

Walton PD, Airey JA, Sutko JL, Beck CF, Mignery GA, Sudhof TC, Deerinck TJ, Ellisman MH (1991) Ryanodine and inositol trisphosphate receptors coexist in avian cerebellar Purkinje neurons. J Cell Biol 113:1145-1157.

Williams DA, Fogarty KE, Tsien RY, Fay FS (1985) Calcium gradients in single smooth muscle cells revealed by the digital imaging microscope using fura-2. Nature 318:558-561.

Williams DA, Becker PL, Fay FS (1987) Regional changes in calcium underlying contraction of single smooth muscle cells. Science 235 : 1644-1648.

Worley PF, Bhat RV, Baraban JM, Erickson CA, McNaughton BL Barnes CA (1993) Thresholds for synaptic activation of transcription factors in hippocampus: correlation with long-term enhancement. J Neurosci 13:4776-4786.

Yu SP, O'Malley DM, Adams PR (1994) M-current regulation by intracellular calcium in bullfrog sympathetic neurons. J Neurosci 14: 3487-3499. 